\title{
Nearshore Wave Simulations and Wave Characteristics Analysis during Extreme Weather Events
}

\author{
Ye Htet $\mathrm{Oo}^{\dagger}$, Hong Zhang ${ }^{\dagger *}$, and Gildas Colleter \\ 'School of Engineering and Built Environment \\ Griffith University \\ Water Technology \\ Victoria 3168, Australia
}

Queensland 4222, Australia

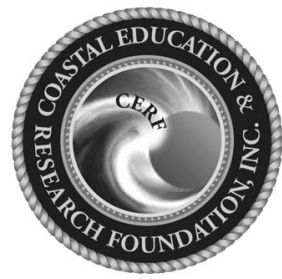

www.cerf-jcr.org

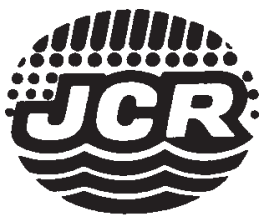

www.JCRonline.org

\begin{abstract}
Oo, Y.H.; Zhang, H., and Colleter, G., 0000. Nearshore wave simulations and wave characteristics analysis during extreme weather events. Journal of Coastal Research, 00(0), 000-000. Coconut Creek (Florida), ISSN 0749-0208.

Offshore storm wave direction may distinguish between an extreme event and a typical event experienced at nearshore. Using a state-of-the-art spectral wave (SW) model, the purposes of this study are: (1) to investigate the transformation of waves from offshore to nearshore along the coastline from two opposite directions (northerly and southerly); and (2) to analyse the offshore wave energy density spectrum. The SW model was calibrated considering various mesh resolutions and lateral wind forcing with different wind field resolutions. The results show that a longshore wave attenuation gradient exists from the southerly swell, primarily due to different degrees of sheltering provided by the headland. In contrast, the coast essentially becomes an open coast from northerly swells, thereby producing a significant reduction in wave attenuation. The wave energy density spectrum indicates that wave pattern varies depending on offshore wave direction. Both storms produce a wide range of frequencies and directions. However, southerly swells only produce single-peaked spectrum, while double-peaked spectrum is observed in northerly swells due to the presence of prevailing swells and storm swells. This study highlights the significant reduction of wave attenuation when predominate offshore wave direction is abrupted.
\end{abstract}

ADDITIONAL INDEX WORDS: Reanalysis wind, wave transformation, wave energy density spectrum, East Coast low.

\section{INTRODUCTION}

Sandy coasts are becoming some of the fastest-growing regions in terms of population, mainly due to ease of access to recreational and lifestyle activities. Compared to inland regions, average population densities are higher in coastal zones (CasasPrat, Wang, and Sierra, 2014). Weather conditions, beach configuration, and external factors such as engineered structures can cause localized erosion or accretion (Castelle, Le Corre, and Tomlinson, 2008), which is one of the biggest challenges for coastal cities such as the Gold Coast in Australia. In order to accurately predict erosion, wave parameters are required. However, monitoring of wave conditions may not be readily available for all locations (Turner et al., 2016). Hence, other prediction tools are required to estimate wave parameters.

In the early days of coastal engineering, waves were predicted through application of empirical formulas (e.g., Hasselmann et al., 1973; Sverdrup and Munk, 1947; U.S. Army, 1984; Wilson, 1965). These methods are relatively simple as they were developed by assuming wave growth under constant wind in deep waters or at constant depth. As such, these methods lack accuracy in complex situations such as in shallow waters (Kamranzad, Etemad-Shahidi, and Kazeminezhad, 2011) where wave transformation, such as refraction and depth-induced wave breaking, takes place. Nowadays, with the advancement of computational technologies, third-generation spectral wave numerical modelling tools

DOI: 10.2112 / JCOASTRES-D-21-00012.1 received 24 January 2021; accepted in revision 24 June 2021; corrected proofs received 3 August 2021; published pre-print online 23 August 2021.

*Corresponding author: hong.zhang@griffith.edu.au

${ }^{\circledR}$ Coastal Education and Research Foundation, Inc. 2021 such as the Simulating Waves Nearshore Model (SWAN) (Allard, Rogers, and Carroll, 2002), MIKE 21 SW (DHI, 2017), Wave Modeling (WAM) (Hasselmann et al., 1988), and Wave Watch III (WW3) (WW3DG, 2016) are fast becoming a powerful tool for wave prediction due to their accuracy, reliability, and above all, cost and efficiency (Venugopal et al., 2011). Also, studies such as Fonseca, Gonçalves, and Guedes Soares (2017), Moeini and Etemad-Shahidi (2007), Padilla-Hernández et al. (2007), Strauss, Mirferendesk, and Tomlinson (2007), Strauss et al. (2007), and Venugopal et al. (2011) have demonstrated the performance of third-generation spectral wave models using both qualitative and quantitative methods. Despite the reliability and wide application of third-generation spectral wave models, the accuracy of the results highly depends on: (1) the quality of input data (e.g., wind forcing, bathymetry); (2) the applied mesh resolution; and (3) the physics employed (e.g., wave breaking) (Rogers et al., 2012).

Accuracy of hindcasted-wave results using a numerical model generally depends on accuracy of wind input (Lavidas and Venugopal, 2018; Moeini, Etemad-Shahidi, and Chegini, 2010; Rusu, Pilar, and Guedes Soares, 2008). Measured wind has not always been the best option. For example, a study conducted by Cavaleri and Bertotti (2006) pointed out that when analysing wind-waves using a numerical model, such as the Mediterranean Sea, the wave results obtained from measured wind are often inaccurate due to land interference. It has also been demonstrated that measured wind might not be the best option for simulating waves in open-coast nearshore environments, such as the nearshore of the Atlantic Ocean (e.g., Campos et al., 2018), the Pacific Ocean (e.g., Wang et al., 2018), and the Indian Ocean (e.g., Aboobacker et al., 2009). Thus, for a numerical model to perform better during extreme 
events, it has been suggested to increase the wind field resolution by applying a reanalysed wind model (Rusu, Bernardino, and Soares, 2014).

Due to very few in situ wind measurements being available (e.g., Campos et al., 2018; Rusu, Bernardino, and Soares, 2014), it is also common to use wind fields extracted from atmospheric models, such as Climate Forecast System Reanalysis. Studies, such as Akpinar and Ponce de León (2016), Lavidas, Venugopal, and Friedrich (2017), Van Vledder and Akpinar (2015), Wang et al. (2018); and Wang, Duan, and Dong (2018) have intercompared various types of modelled winds. In general, these studies have verified that, while using a numerical model to generate waves, one type of wind forcing may not fit for all wave conditions (such as long-term or upper percentiles). Stopa and Cheung (2014) analysed two reanalysis winds (European Centre for Medium-Range Weather Forecasts [ECMWF] and National Centers for Environmental Prediction [NCEP]) against buoy and altimetry measurements. They concluded that ECMWF modelled wind, which has spatial resolution of $0.7^{\circ}$, had better homogeneity, and was therefore more reliable for modelling long-term processes, whereas NCEP modelled wind that has $0.3^{\circ}$ spatial resolution was better in the upper percentiles that are associated with extreme events. This demonstrates that when hindcasting waves using a numerical model, selection of wind resolution is important depending on the nature of study (e.g., long-term or upper percentiles).

Accurate prediction of wave climates is essential for studying nearshore processes such as storm-induced beach erosion. Some numerical based studies (e.g., Lewis et al., 2010; Sedigh et al., 2016, 2015; Strauss, Mirferendesk, and Tomlinson, 2007; Splinter et al., 2014; Strauss et al., 2007) lack sensitivity analysis of wind forcing and mesh resolution at the Gold Coast waters. Selection of a wind forcing is important for waves transforming near a coast, as emphasized by previous studies mentioned above. Furthermore, these studies either focus wave transformation on one particular site (rather than spatial) to study nearshore process (e.g., beach erosion) or compare the performance of the third-generation numerical wave models (e.g., SWAN and MIKE 21) or study the spatial wave transformation for a one-time step (rather than time series wave transformation). Nearshore processes are normally not an isolated process and spatial wave transformation is required to further enhance the understanding of nearshore processes. Therefore, by addressing the Gold Coast coastal region as a study domain, the aims of this study are to: (1) evaluate the effect of different wind conditions and (2) study wave transformation from two different offshore wave propagation directions (northerly and southerly) to nearshore and analyse the offshore energy spectrum during extreme weather events, using a numerical model.

\section{Study Area and Field Data}

Gold Coast City is a coastal city located at the corner of southeast Queensland, Australia. It is a famous tourist destination and beach resort both nationally and internationally due to the quality of its sandy beaches and perfect wave conditions for surfers. Gold Coast's coastline is nonlinear and its sand is classified as fine quartz (Strauss and Tomlinson, 2009). It is orientated in a north-south direction with land at the west and sea at the east. The coastline stretches approximately $54 \mathrm{~km}$ from southern Stradbroke Island in the north to Coolangatta in the south, with the coordinates of $153.449^{\circ} \mathrm{E}, 27.738^{\circ} \mathrm{S}$ and $153.552^{\circ} \mathrm{E}, 28.165^{\circ} \mathrm{S}$, respectively. The study domain covers approximately $4721 \mathrm{~km}^{2}$, as shown in Figure 1.

Along the east coast of Australia, weather patterns dominate sea-wave and swell-wave formation (Vieira Da Silva, Murray, and Strauss, 2018). During summer, tropical cyclones are formed, while in winter east coast lows (ECLs) are formed. According to Allen and Callaghan (1999), tropical cyclones are not generally responsible for high-wave events on the Gold Coast (although damaging events may be observed due to longer durations or frequency of occurrence), but ECLs are the most common storms (Castelle, Le Corre, and Tomlinson, 2008) that are potentially damaging along the east coast of Australia (Burston, Taylor, and Garber, 2016). Although they are generally formed during winter, under the right conditions they can occur at any time (Allen and Andrews, 1997; Lewis et al., 2010). They are normally short-lived (lasting several days) (Splinter and Palmsten, 2012), but they can bring heavy rainfall, strong wind gusts $(>130 \mathrm{~km} / \mathrm{hr}$ ) (Mortlock et al., 2017), high waves, and storm surges. The swells generated by an ECL normally approach the shore from a south to southeast direction (Mortlock et al., 2017) and these directions are also the predominant wave direction for the current study domain (Splinter et al., 2014). Since the Gold Coast's coastline is nonlinear, the impact of waves generated by the ECL storms varies along the coast (Turner, Aarninkhof, and Holman, 2006).

Within the study domain, two wave measurement buoys record the incoming wave signals: the Gold Coast buoy (GC) $\left(153.443^{\circ} \mathrm{E}, 28.965^{\circ} \mathrm{S}\right)$ at the north and the Tweed Heads buoy $(\mathrm{TH})\left(153.576^{\circ} \mathrm{E}, 28.182^{\circ} \mathrm{S}\right)$ at the south, as marked in Figure 1. Both these buoys record significant wave height $\left(H_{s}\right)$ and corresponding peak period $\left(T_{p}\right)$ and wave direction $(\theta)$. Due to an open-coast environment and limited numbers of buoys, a high-precision wave model is necessary for this study area for predicting beach erosion.

\section{Extreme Wave Analysis}

According to Mortlock et al. (2017), the June 2016 ECL was an unusual weather system that impacted $2000 \mathrm{~km}$ of the eastern seaboard of Australia. Although little activity was reported on the Gold Coast beaches, this weather system caused the worst coastal erosion in 40 years at some beaches in the neighbouring state of New South Wales (Mortlock et al., 2017). The intensity of the storm was indicated by the average return interval (ARI) of $H_{s}$. The ARI of the measured offshore (90 $\mathrm{m}$ depth) $H_{s}$ produced by the June 2016 ECL storm was approximately two years, corresponding to approximately $6.5 \mathrm{~m}$ and a period around $14 \mathrm{~s}$; however, due to the shift in storm wave direction (from southerly to northerly), the ARI was significantly higher (approximately 30 years) (Mortlock et al., 2017). For the synoptic of the weather pattern, readers are referred to Mortlock et al. (2017). Therefore, the storm condition of the June 2016 ECL will be used as one of the wave directions.

\section{METHODS}

In this section, a general introduction of applied spectral wave (SW) for propagating offshore to nearshore waves is 
(a)

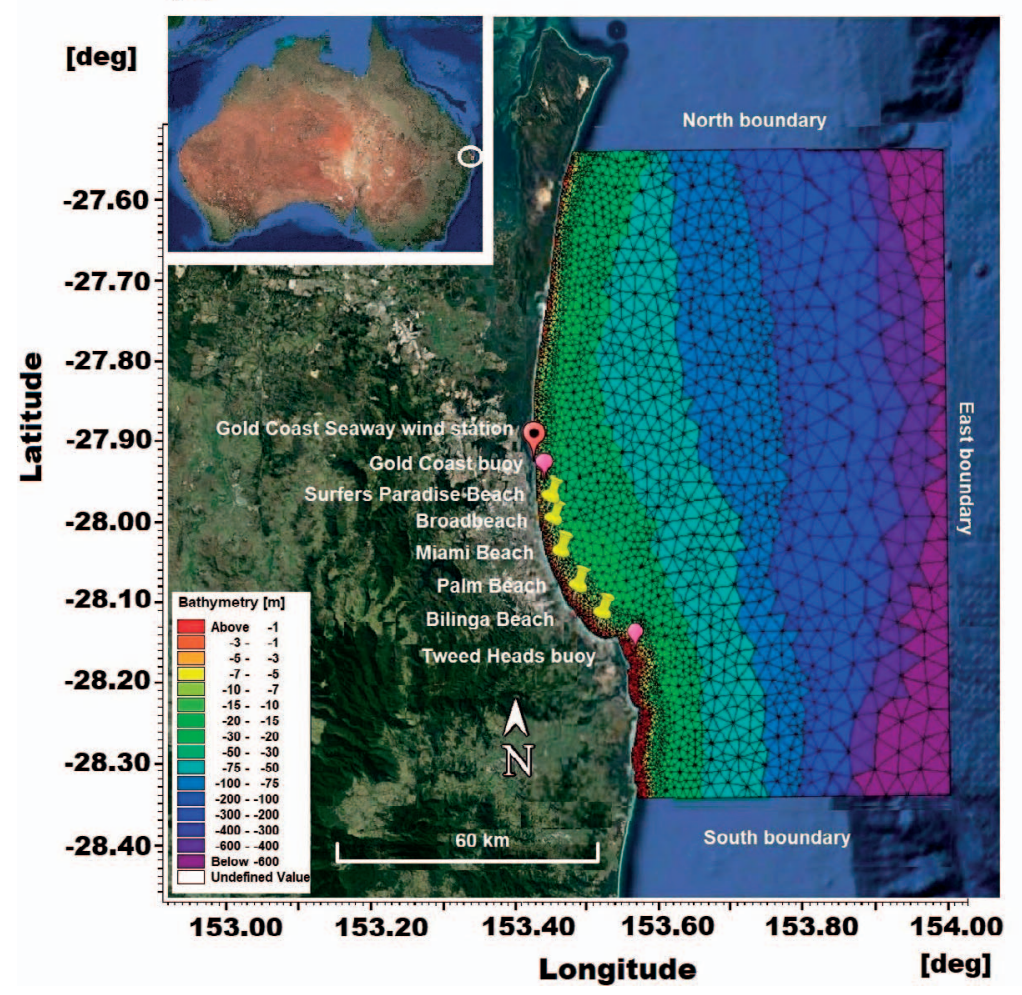

(b)

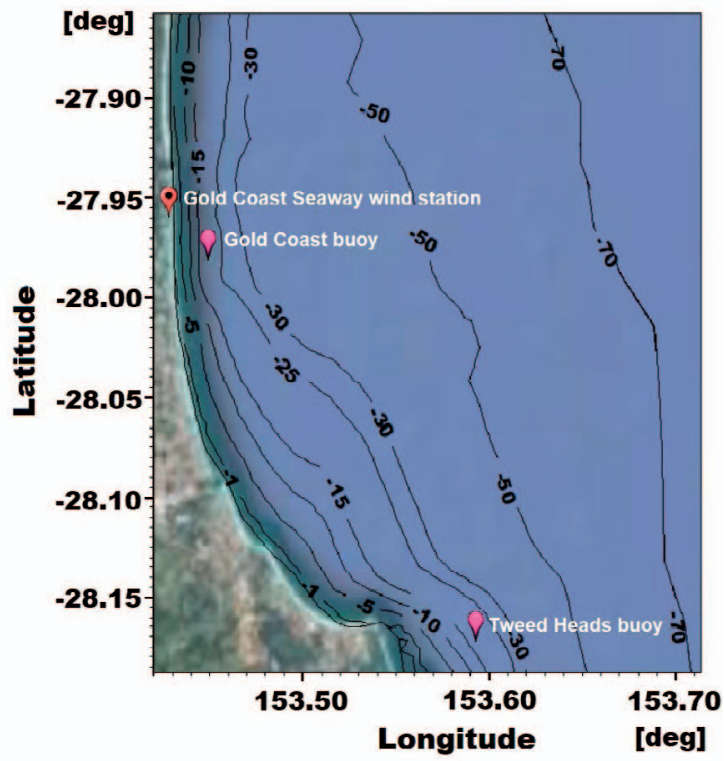

Figure 1. (a) Study domain showing the applied bathymetry (datum: mean sea surface level) and mesh resolution. The locations of well-known beaches are shown with yellow pins. (b) Gold Coast water bathymetry up to $-70 \mathrm{~m}$. The location of measured wind and wave buoys are also pinned. (Source: background Google Earth)

presented, followed by presenting model inputs: bathymetry and mesh, and time series of applied forcing (wave and wind parameters). Also, various statistical performances for model evaluations are also presented in this section.

\section{Spectral Wave Model}

A third-generation spectral wave model, MIKE 21 SW (DHI, 2017) with unstructured meshes (hereafter referred to as MIKE), was applied for wave simulation on the Gold Coast with time-step of 30 minutes. The model simulates the growth, decay, and transformation of wind-generated waves and swells for both offshore and coastal areas. The governing equation is the wave action balance equation, where the wave field is represented by the wave action density spectrum. The wave energy density spectrum $(E)$ and the wave action density $(N)$ relationships are shown in Equation (1) and Equation (2). Cartesian coordinates are used as the length of the domain is less than $100 \mathrm{~km}$ :

$$
\begin{gathered}
N=\frac{E}{\sigma} \\
\frac{\partial N}{\partial t}+\nabla \cdot(\vec{v} N)=\frac{S}{\sigma}
\end{gathered}
$$

where, $\sigma=2 \pi f, \theta$ is the direction of wave propagation, $t$ is the time, $\vec{x}=(x, y)$ are the Cartesian coordinates, $\vec{v}=\left(c_{x}, c_{y}, c_{\sigma}, c_{\theta}\right)$ is the propagation velocity of a wave group in the four dimensional phase space $\vec{x}, \sigma$ and $\theta, \nabla$ is the four-dimensional differential operator in the $\vec{x}, \sigma, \theta$ space, and the source term $(S)$ is the sum of source functions, which are as follows:

$$
S=S_{\text {in }}+S_{\mathrm{nl}}+S_{\mathrm{ds}}+S_{\mathrm{bot}}+S_{\mathrm{surf}}
$$

where, $S_{\text {in }}$ is the energy generated by wind, $S_{\mathrm{nl}}$ is the wave energy transfer due to nonlinear wave-wave interaction, and $S_{\mathrm{ds}}, S_{\mathrm{bot}}$, and $S_{\text {surf }}$ are the dissipation of wave energy due to whitecapping, bottom friction, and depth-induced breaking, respectively (DHI, 2017).

\section{Bathymetry and Model Mesh}

The domain and bathymetry applied for model simulation is shown in Figure 1a. The bathymetry data was obtained from Geoscience Australia with an interval of approximately $250 \mathrm{~m}$ and the datum was the mean sea surface level (Jarvis et al., 2008). As can be seen in Figure 1, the cross-sectional bathymetry gradient varies along the coast, but north of the headland (between $28^{\circ} \mathrm{S}$ to $28.16^{\circ} \mathrm{S}$ ), the slope decreases. The depth up to $15 \mathrm{~m}$ around the GC buoy increases so rapidly that only a thin strip of isobaths can be observed. In addition, the isobaths nearshore (up to a depth of $30 \mathrm{~m}$ ) are parallel to the shoreline. The average slope up to a depth of $7 \mathrm{~m}$ is approximately 1:110 and the average slope up to a depth of $600 \mathrm{~m}$ is approximately 1:74. 
In this study, an unstructured mesh with four zones (i.e. different levels of mesh resolution) was applied. The resolution of an unstructured mesh is subjective; however, in this study four mesh zones were applied (see Figure 1a). The applied mesh, shown in Figure 1a, was constructed with 4205 elements and 2234 nodes. The region of interest (i.e. nearshore) was set up with finest mesh resolution due to intensive wave transformation (Lisboa, Teixeira, and Fortes, 2017). This mesh resolution had the node distance of $\sim 0.6 \mathrm{~km}$. Then, the node distance increased by 2 (i.e. became coarser) in an offshore direction since wave transformation becomes smaller due to less interaction with the bathymetry. The sensitivity analysis of spatial resolution was carried out and discussed in the "Sensitivity Analysis" section. In this study, the inner boundary of the outmost (offshore) nested zone followed 100 $\mathrm{m}$ isobaths and the inner boundary of the second outmost nested mesh followed $50 \mathrm{~m}$ isobaths. The third inner mesh boundary was drawn parallel to shore.

\section{Boundary Conditions}

During the model setup, a few assumptions were made. It was assumed that (1) there was no interaction with freshwater discharge from creeks or rivers and wave propagation towards the shore was fully absorbed (DHI, 2017); (2) due to a relatively short simulation time, changes in bathymetry were not considered (i.e. out of scope for this study), and (3) variations in water level and current were also not considered. Thus, the wave and wind forcing are the dominant parameters in simulating waves within this study domain and they are discussed in the following subsection. In this study, true north is considered as $0^{\circ}$ (coming from) with clockwise direction as positive.

\section{Wave Conditions at Open Boundaries}

The open boundaries of the study domain were enclosed by the north boundary (NB), the south boundary (SB), and the east boundary (EB) (see Figure 1a). The lateral boundary condition was applied at NB and SB, where incoming wave information $\left(H_{\mathrm{s}}, T_{p}\right.$, and $\left.\theta\right)$ is obtained from the connected boundary lines by solving one-dimensional basic equations (DHI, 2017). The nodes at EB were forced with offshore wave conditions across the boundary and these data were extracted from the WW3 Global Wave Model, made available by the Pacific Islands Ocean Observing System (PacIOOS) (Cheung, 2010). It is a global wave model that forecasts hourly wave fields with $\sim 50 \mathrm{~km}$ spatial resolution. The PacIOOS's boundary waves will be denoted as WW3 hereinafter. For the current study domain, only one WW3 point was available within the study domain due to the spatial resolution of WW3. The point time series extracted from WW3 was located at $154^{\circ} \mathrm{E}$ and $28^{\circ} \mathrm{S}$. The wave parameters applied at the EB were significant wave height $\left(H_{\mathrm{s}}\right)$, the corresponding $\operatorname{period}\left(T_{p}\right)$, and wave direction $(\theta)$.

Prior to applying WW3 for further analysis, feasibility of one other offshore wave model was also assessed, which was ECMWF Reanalysis (ERA5) (Copernicus Climate Change Service [C3S], 2017). ERA5 is the fifth-generation global model that estimates atmospheric ( $\sim 30 \mathrm{~km}$ resolution), land, and oceanic climate variables ( $\sim 50 \mathrm{~km}$ resolution). It covers data from 1950 to the present with one hour temporal resolution (C3S, 2017). The time series of extracted offshore
WW3 and ERA5, their respective simulated model results, and the measured GC buoy is shown in Figure 2. The model simulation procedure for WW3 will be discussed in the "Model Validation" section. From Figure 2, the result clearly indicate that ERA5 time series results underestimated the wave height nearshore due to the underestimation of offshore wave height. For this reason, WW3 was implemented for further analysis.

\section{Wind Data}

In this study, measured and reanalysed winds were considered. For measured wind, the Gold Coast Seaway wind dataset was applied, which is located at the coordinate $153.428^{\circ}$ $\mathrm{E}, 27.939^{\circ} \mathrm{S}$ (see also Figure 1a). This measured wind is used as a baseline with which the model is calibrated. These measured datasets were acquired from the Australian Government Bureau of Meteorology with temporal resolution of one minute. The wind parameters (speed: $U$ and direction: $\theta_{\text {wind }}$ ) are recorded at an elevation of $3 \mathrm{~m}$. Prior to implementing the wind parameters for model simulations, the wind speeds were converted to $10 \mathrm{~m}$ elevation, and this is denoted as $U_{10}$. It should be noted that during numerical simulation using baseline wind (i.e. point measured wind), it was assumed that there was a spatial constant within the domain for each time step.

As wind is one of the major energy sources in generating waves, two reanalysed wind datasets were also studied during sensitivity analysis, which are ERA5 and the Bureau of Meteorology Atmospheric High-Resolution Regional Reanalysis for Australia (BARRA) (Su et al., 2019). Feasibility of ERA5 was particularly assessed since, according to Ramon et al. (2019), ERA5 provided the best agreement with the in situ observations. BARRA is chosen as another wind source since it is a high-resolution regional reanalysis and is specifically designed for the Australian region. The dataset has been available since 1990 with a spatial and temporal resolution of $12 \mathrm{~km}$ and six hours, respectively. Compared to ERA5, BARRA has finer spatial resolution; however, it has lower temporal resolutions. It should be noted that during the sensitivity study for ERA5 and BARRA, unlike baseline wind, spatial variation (within the study domain) was applied for each time step.

\section{Model Performance Evaluation}

The skill of the model was assessed by using statistical analyses that are commonly practiced among researchers. The adopted statistical analyses in this study were: correlation coefficient (R), root-mean-square error (RMSE), scatter index (SI), and bias (BI). The respective equations are as follows:

$$
\begin{gathered}
\mathrm{R}=\frac{\sum_{i=1}^{n}\left(M_{i}-\bar{M}\right)\left(S_{i}-\bar{S}\right)}{\sqrt{\sum_{i=1}^{n}\left(M_{i}-\bar{M}\right)^{2} \sum_{i=1}^{n}\left(S_{i}-\bar{S}\right)^{2}}} \\
\mathrm{RMSE}=\sqrt{\frac{\sum_{i=1}^{n}\left(M_{i}-S_{i}\right)^{2}}{n}} \\
\mathrm{SI}=\frac{\mathrm{RMSE}}{\bar{M}}
\end{gathered}
$$




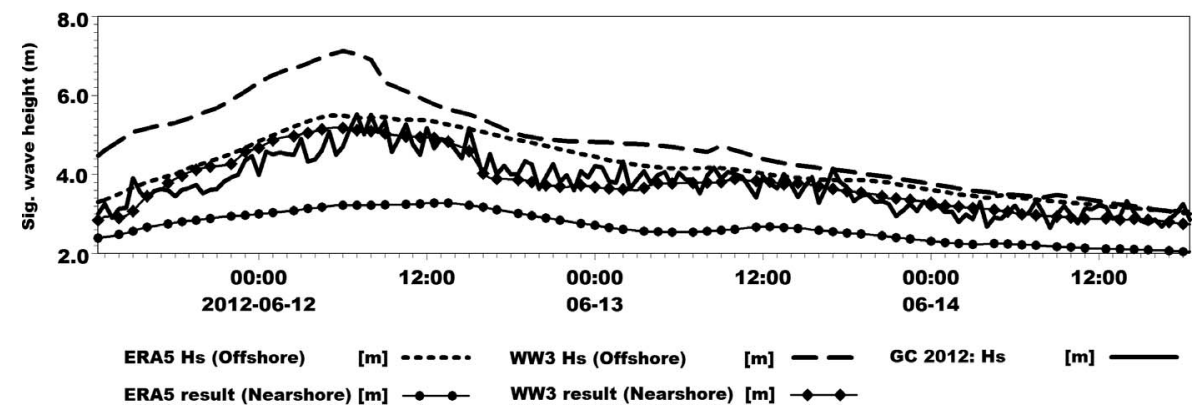

Figure 2. Time series point output of offshore WW3 and ERA5 extracted at $154^{\circ} \mathrm{E}$ and $28^{\circ} \mathrm{S}$ and their respective simulated model results, along with GC time series is presented.

$$
\mathrm{BI}=\frac{\sum_{i=1}^{n}\left(M_{i}-S_{i}\right)}{n}
$$

where, $M_{i}$ and $\overline{\mathrm{M}}$ denote the individual and mean value of measured data, $S_{i}$ and $\overline{\mathrm{S}}$ denote the individual and mean value of simulated data, respectively, and $n$ is the number of observations.

\section{Model Validation}

In this section, the wave conditions applied for the SW model during calibration and verification are discussed. The forcing implemented for the SW model during calibration and verification are also presented.

\section{Model Calibration}

The storm $H_{s}$ in this study was defined as $3 \mathrm{~m}$ that lasted at least one hour in duration, based on definitions of a storm by Callaghan et al. (2008) and Karunarathna et al. (2014). For calibration, the storms generated between 11 June 2012 and 14 June 2012 (i.e. duration of $\sim 3$ days) were selected, as detailed in Table 1. Time series wind conditions are shown in Figure 3a. The measured maximum $H_{s}$ was approximately $5.52 \mathrm{~m}(5.2 \mathrm{~m})$ at GC (TH) and according to Granger and Hayne (2001), these wave heights had an ARI of approximately five years. The measured $H_{s}, T_{p}$, and $\theta$ at GC (TH) were on average $3.56 \mathrm{~m}$ $(3.36 \mathrm{~m}), 12 \mathrm{~s}(11.9 \mathrm{~s})$, and $94.3^{\circ}\left(83.8^{\circ}\right)$, respectively. In terms of offshore waves, the predicted WW3 peaked $H_{\mathrm{s}}$ at the model boundary was approximately $7 \mathrm{~m}$, with an average $H_{\mathrm{s}}, T_{p}$, and $\theta$ of $4.7 \mathrm{~m}, 11.6 \mathrm{~s}$, and $113.13^{\circ}$, respectively. The maximum $U_{10}$ measured during calibration was $14.3 \mathrm{~m} / \mathrm{s}$, with average $U_{10}$ and $\theta_{\text {wind }}$ of $6.6 \mathrm{~m} / \mathrm{s}$ and $195^{\circ}$, respectively.

By forcing the EB nodes with the time series extracted from WW3 between 11 June 2012and 14 June 2012, the model was calibrated using the values described in Table 2 . The calibration and results will be discussed in next section. In Table 2, a constant value for each parameter was applied to the

Table 1. Details of observed storms applied in this study. whole domain. Due to the open coast environment, the diffraction is assumed to be negligible and will not be considered in this study. The bottom friction coefficient was assumed to be based on median sediment grain size $\left(D_{50}\right)$, which was $0.2 \mathrm{~mm}$. Such a partial size was applied based on previous study (Sedigh et al., 2016). Furthermore, Strauss and Tomlinson (2009) reported that the sand in the Gold Coast region is classified as fine quartz with $D_{50}$ approximately 0.22 mm and, according to Turner, Aarninkhof, and Holman (2006), the sediment along the Gold Coast is composed of well-sorted fine sand with $D_{50}$ approximately $0.2 \mathrm{~mm}$.

\section{Model Verification}

The model verification was performed to quantify the reliability of the model's predictions. For the verification run, the storm that occurred between 28 June 2012 and 29 June 2012 was applied, which was the successive calibration storm. This storm lasted for more than a day and the measured maximum $H_{\mathrm{s}}$ at GC (TH) was approximately $4.57 \mathrm{~m}(4.16 \mathrm{~m})$. According to Granger and Hayne (2001), this storm $\left(H_{\mathrm{s}}\right)$ had an ARI of two years. The offshore EB nodes were forced with WW3 time series $H_{\mathrm{s}}, T_{p}$, and $\theta$, which had an average value of $4.6 \mathrm{~m}$, $11.1 \mathrm{~s}$, and $133^{\circ}$, respectively. The applied time series wind condition is shown in Figure $3 \mathrm{~b}$. The maximum measured $U_{10}$ was approximately $18.3 \mathrm{~m} / \mathrm{s}$, with average $U_{10}$ and $\theta_{\text {wind }}$ of 12 $\mathrm{m} / \mathrm{s}$ and $156^{\circ}$, respectively. The simulated time series verification results are presented in next section.

\section{RESULTS}

In this section, the results for model calibration and verification are initially presented. The sensitivity analysis performed for model parameters are then discussed, followed by extreme weather analysis results. Finally, the wave transformation and wave energy density spectrum results are presented.

\begin{tabular}{|c|c|c|c|c|c|}
\hline & \multirow[b]{2}{*}{ Begin (Day and Hour) } & \multirow[b]{2}{*}{ End (Day and Hour) } & \multirow[b]{2}{*}{ Duration (days) } & \multicolumn{2}{|c|}{ Max Wave Height (m) } \\
\hline & & & & GC & $\mathrm{TH}$ \\
\hline Calibration (June 2012) & 11,1230 & 14,1815 & $\sim 3.25$ & 5.52 & 5.2 \\
\hline Verification (June 2012) & 27,2230 & 29,1140 & $\sim 1.5$ & 4.57 & 4.16 \\
\hline June 2016 ECL & 4,0500 & 6,0430 & $\sim 2$ & 5.14 & 5.57 \\
\hline
\end{tabular}




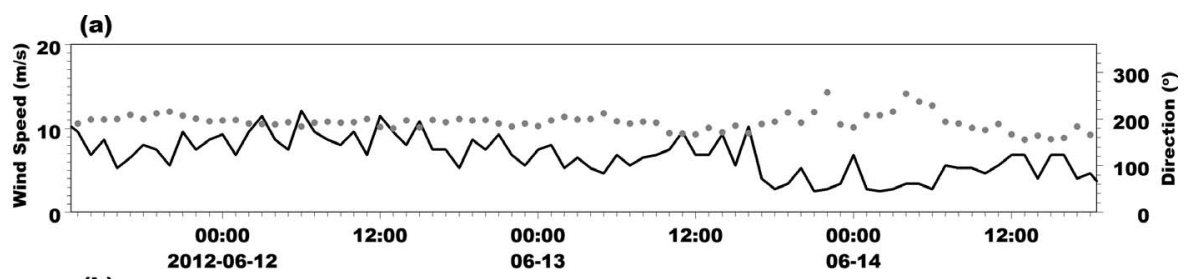

(b)

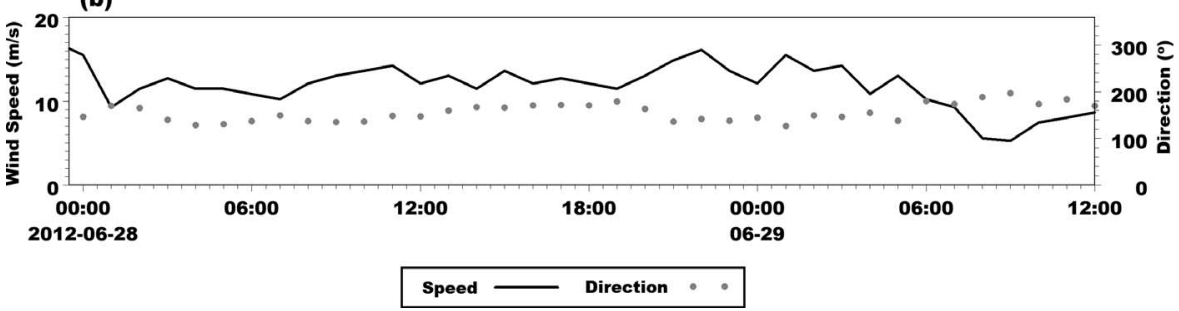

Figure 3. Measured wind speed and direction during (a) calibration and (b) verification.

\section{Model Calibration}

During model calibration, the time series offshore measured wind and WW3 wave parameters were applied. The wind time series plot is presented in Figure 3a and the time series calibrated model results, including the offshore wave boundary conditions (WW3) and measured buoy parameters, are shown in Figure 4 for both GC and TH.

Based on qualitative assessment (see Figure 4), some inconsistencies are noticed. For instead, variation in simulated $H_{s}$ at both sites changed more gradually than measured data, which had a sharp change. This could be due to offshore $H_{s}$, where the gradual change was also observed (see Figure 4). Variations were also observed between measured TH and GC for $T_{p}$, which could be due to localized wind effects. However, near identical $T_{p}$ results were simulated by the model for both buoy locations since localized effects were not simulated by the model and constant offshore forcing were applied for each time step at EB nodes.

The performance of the calibrated model at both the GC and TH buoys (i.e. point outputs) were also evaluated against their respective measured parameters using Equations (4-7), and the results are presented in Table 3. From this table, the correlation coefficient $(R)$ of wave height showed the strongest relationship for both stations, while wave direction showed the least strong relationship. Also, the positive (negative) BI of each parameter indicated the model underestimated (overestimated) the measured data. Despite showing some disagree-

Table 2. Energy coefficient of MIKE 21 SW applied values during calibration against the default values.

\begin{tabular}{lll}
\hline \hline \multicolumn{1}{c}{ Parameters } & \multicolumn{1}{c}{ Calibrated } & \multicolumn{1}{c}{ MIKE Default } \\
\hline Diffraction coefficient (D) & Not required & No \\
Wave breaking index (WB) & $\gamma=1.5, \alpha=0.5$ & $\gamma=0.8, \alpha=0.5$ \\
Whitecapping (WC) & $C_{\text {dis }}=1$, Delta $=0.5$ & $C_{\text {dis }}=1$, Delta $=0.5$ \\
Bottom friction coefficient (F) & $D_{50}=0.2 \mathrm{~mm}$ & $D_{50}=0.25 \mathrm{~mm}$ \\
\hline
\end{tabular}

Where, $\gamma$ and $\alpha$ are breaker parameter and calibration constant, respectively. $C_{d i s}$ and Delta are dispersion coefficients. $D_{50}$ is the median grain size. ment due to offshore forcing and assumptions made, this model was used for further analysis.

\section{Model Verification}

The time series results of verification, along with the WW3 and measured wave, are shown in Figure 5. The qualitative assessment showed that the model tends to overestimate wave height before and after the peak of a storm. The peak of the storm (i.e. where $H_{\mathrm{s}}$ remained relatively constant) was between 0000 hours and 0600 hours on 29 June 2012 (refer to Figure 5). During the aforementioned periods, the model closely followed the measured $H_{\mathrm{s}}$. For the $T_{p}$, the model prediction was reasonably accurate. However, for the $\theta$, overestimation was observed initially (i.e. between 0000 and 0900 hours on 28 June 2012), but the model prediction then followed closely to the measured $\theta$ for the remaining time series. The skill of the model was also quantified using the statistical analyses provided in Equations (4-7), and the results are presented in Table 3. Based on the results presented in Table 3, except for R, other error analyses (RMSE, SI, and BI) performed well. In terms of $\mathrm{R}$, the performance of $H_{\mathrm{s}}$ was reduced at both stations, but $\theta$ was reduced only at TH. One of the significant contributions for lowering $\mathrm{R}$ could be due to measured data taking into consideration local effects (i.e. noises). Other factors included inaccurate offshore wave prediction and use of constant energy dissipation coefficients (refer to Table 2).

\section{Sensitivity Analysis}

To improve the performance of the wave prediction, sensitivity of a few model parameters and wind forcing were further analysed. They were mesh resolution, wave breaking index, and reanalysed winds (ERA5 and BARRA) and the analysed results are presented below.

\section{Mesh Resolution}

The resolution of the applied mesh is described in the "Bathymetry and Model Mesh" section. In this section, various mesh resolutions were analysed prior to the mesh resolution applied in this study. Various mesh resolutions were required for the analysis since mesh resolution affects the accuracy of a 


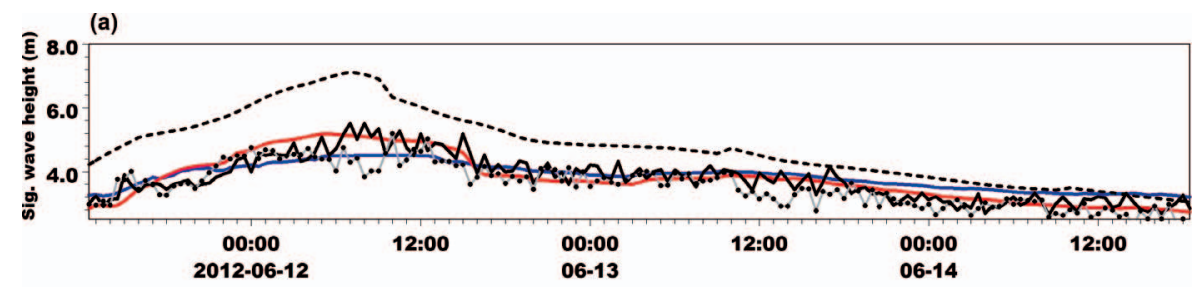

(b)

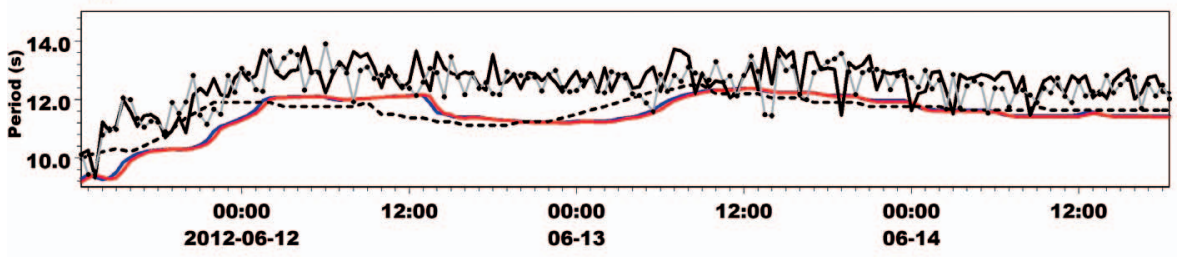

(c)

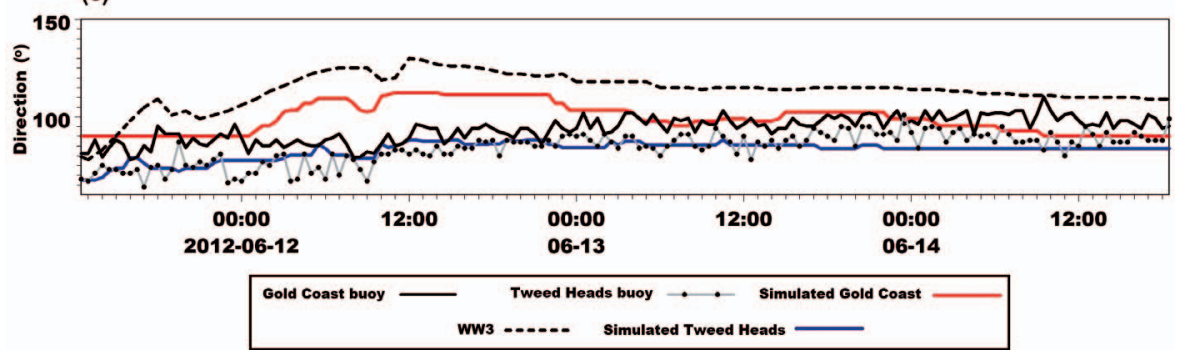

Figure 4. Calibrated wave results superimposed with measured buoy parameters and WW3.

numerical wave model (e.g., Aydoğan and Ayat [2018] and Lisboa, Teixeira, and Fortes [2017]), especially at the nearshore. Cavaleri (2009) also mentioned that increasing mesh resolution provided better agreement for the storm peaks. On the other hand, Kerr et al. (2013) mentioned that they did not find any increase accuracy in prediction wave height. Due to such contradiction, a few mesh sensitivities were analysed.

In this study, the unstructured mesh, which provides flexibility with the mesh resolution, was applied. This type of

Table 3. Detailed model performance using Equations (4-7) for both GC and TH for calibration, verification, and June 2016 ECL based on half hourly time series.

\begin{tabular}{|c|c|c|c|c|c|c|}
\hline & \multicolumn{3}{|c|}{ GC } & \multicolumn{3}{|c|}{$\mathrm{TH}$} \\
\hline & $H_{s}$ & $T_{p}$ & $\theta$ & $H_{s}$ & $T_{p}$ & $\theta$ \\
\hline \multicolumn{7}{|c|}{ Calibration } \\
\hline $\mathrm{R}$ & 0.90 & 0.74 & 0.59 & 0.87 & 0.73 & 0.67 \\
\hline RMSE & $0.31 \mathrm{~m}$ & $1.21 \mathrm{~s}$ & $14.19^{\circ}$ & $0.46 \mathrm{~m}$ & $1.05 \mathrm{~s}$ & $6.72^{\circ}$ \\
\hline SI & 0.08 & 0.10 & 0.15 & 0.13 & 0.08 & 0.08 \\
\hline $\mathrm{BI}$ & $-0.01 \mathrm{~m}$ & $1.08 \mathrm{~s}$ & $-10.92^{\circ}$ & $-0.28 \mathrm{~m}$ & $0.90 \mathrm{~s}$ & $3.34^{\circ}$ \\
\hline \multicolumn{7}{|c|}{ Verification } \\
\hline $\mathrm{R}$ & 0.75 & 0.83 & 0.63 & 0.54 & 0.72 & 0.41 \\
\hline RMSE & $0.33 \mathrm{~m}$ & $0.53 \mathrm{~s}$ & $13.49^{\circ}$ & $0.45 \mathrm{~m}$ & $0.54 \mathrm{~s}$ & $8.57^{\circ}$ \\
\hline SI & 0.09 & 0.05 & 0.16 & 0.13 & 0.05 & 0.11 \\
\hline $\mathrm{BI}$ & $-0.17 \mathrm{~m}$ & $0.29 \mathrm{~s}$ & $-10.82^{\circ}$ & $-0.33 \mathrm{~m}$ & $0.09 \mathrm{~s}$ & $-0.33^{\circ}$ \\
\hline \multicolumn{7}{|c|}{ June 2016 ECL } \\
\hline $\mathrm{R}$ & 0.93 & 0.88 & 0.77 & 0.89 & 0.86 & 0.68 \\
\hline RMSE & $0.38 \mathrm{~m}$ & $1.25 \mathrm{~s}$ & $9.51^{\circ}$ & $0.62 \mathrm{~m}$ & $1.20 \mathrm{~s}$ & $25.39^{\circ}$ \\
\hline SI & 0.17 & 0.11 & 0.10 & 0.27 & 0.11 & 0.28 \\
\hline $\mathrm{BI}$ & $0.03 \mathrm{~m}$ & $0.97 \mathrm{~s}$ & $5.57^{\circ}$ & $-0.36 \mathrm{~m}$ & $0.71 \mathrm{~s}$ & $22.33^{\circ}$ \\
\hline
\end{tabular}

mesh allows the resolution to be defined according to the domain features, such as increasing the mesh resolution where the bathymetry effect became dominant (i.e. nearshore). The spatial resolution was tested until simulated results of $H_{s}, T_{p}$, and $\theta$ at both buoy stations reached insignificant differences. For sensitivity of mesh resolution, three different types with multizone resolution were examined, and they are named as follows: medium-sized mesh (MM); coarse-sized mesh (CM); and finer-sized mesh (FM). Within each type, the offshore zone had the coarsest resolution (areas with the least wave transformation), and resolution became finer nearshore (i.e. region of interest and the most complex bathymetry), as demonstrated in Figure 6. Details of the mesh resolution for CM, FM, and MM are provided in Table 4.

The MM, as shown in Figure 6b, was initially generated as baseline mesh. To evaluate the accuracy of the MM for the entire study domain, two additional meshes, CM and FM, were also generated (refer to Figure $6 \mathrm{a}, \mathrm{c}$ ). The number of nodes and elements (i.e. resolution) for each zone were varied by a factor of approximately 2 with respect to MM (see also Table 4). The mesh resolutions were determined by how dominant the bottom effects were. The offshore zone was where the bathymetry effect was not dominant. Also, this zone was not the area of interest; therefore, coarser mesh resolution was generated. Moving towards shore, the mesh resolution increased due to the increase in bottom effect. Another reason for applying different mesh resolution zones was to save some computational time. 

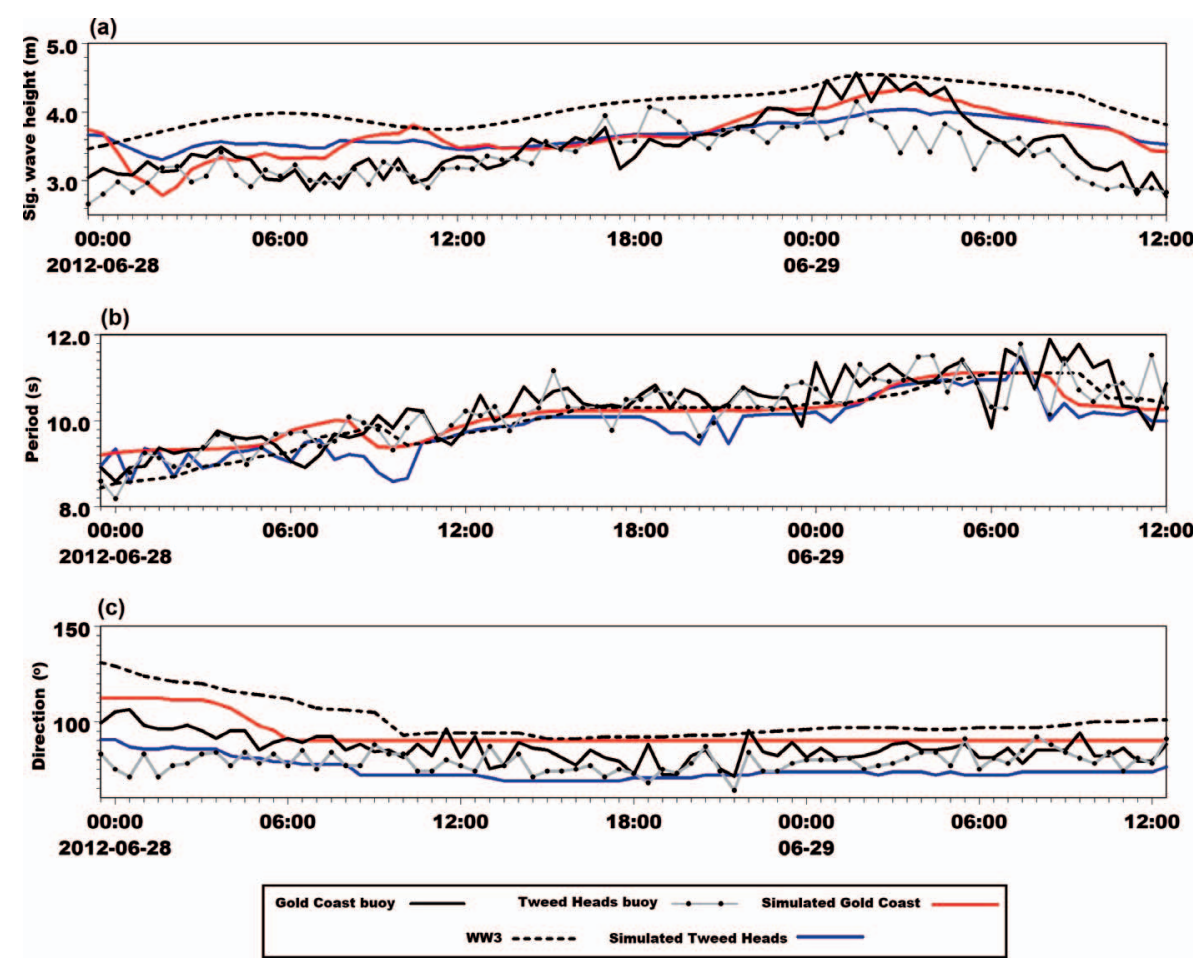

Figure 5. Verified wave results superimposed with measured buoy parameters and WW3.

During the sensitivity study of the meshes, the other two meshes were also simulated with the calibrated parameters provided in Table 2 and the sensitivity of the $H_{\mathrm{s}}$ was evaluated. The difference between CM and MM and the difference between FM and MM for the whole domain for a one-time step was compared at the peak of the storm and the results are presented in Figure 7. In order to study the whole domain, the results were required to interpolate into grids approximately $220 \mathrm{~m}$ by $330 \mathrm{~m}$ since different numbers of nodes and elements were applied for each mesh.

The result of spatial distribution shown in Figure 7a is the $H_{\mathrm{s}}$ difference between $\mathrm{CM}$ and MM, and Figure 7b represents the $H_{\mathrm{s}}$ difference between $\mathrm{FM}$ and $\mathrm{MM}$ during the peak of the calibrated storm on 12 June 2012 (as marked in Figure 7c with an arrow). Figure $7 \mathrm{a}, \mathrm{b}$ demonstrates that from offshore to

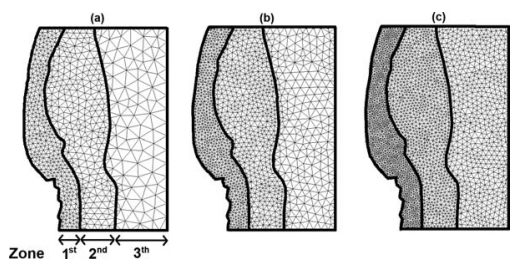

Figure 6. Various mesh resolutions applied during sensitivity analysis. (a) The boundary of each zone extends and the details of nodes and elements, as well as resolution, are provided in Table 4. nearshore where bottom effect was still negligible, the $H_{\mathrm{s}}$ differences were not significant (i.e. $H_{s}$ differences between $0.25 \mathrm{~m}$ and $-0.25 \mathrm{~m}$ ). However, at the nearshore where the bottom effects dominated, the $H_{s}$ differences dramatically changed with potentially more than $1.5 \mathrm{~m}$ for $\mathrm{CM}$ and $-1.5 \mathrm{~m}$ for FM. The time series wave height variation of the three analysed mesh types at a nearshore point (coordinates: 153.44 , $-28.00^{\circ}$, marked with an arrow in Figure $7 \mathrm{a}$ ) was plotted in Figure 7c. This point was chosen since it was one of the areas where considerable variation of $H_{s}$ observed (up to $1.50 \mathrm{~m}$, see Figure 7a). Figure 7 a shows that as the storm wave height increases, the variation in wave height becomes noticeable, with CM's wave height the highest, followed by the baseline mesh and FM.

Therefore, it can be concluded that during high swells, applying $\mathrm{CM}$ could be overestimating $H_{s}$ along the nearshore (refer to Figure 7a, c). Judging the nearshore result in Figure $7 \mathrm{~b}$, c gave the impression that MM resolution along the coastline was still overestimating, particularly at the north and south side of the study domain. Since the model was showing

Table 4. Various mesh resolutions applied for the mesh sensitivity analysis.

\begin{tabular}{lrccccc}
\hline \hline & & & \multicolumn{3}{c}{$\begin{array}{c}\text { Nested Mesh Nodes } \\
\text { Distance }(\mathrm{km})\end{array}$} \\
\cline { 4 - 7 } \multicolumn{1}{c}{ Type of Mesh } & Node & Element & 1st & 2nd & 3rd \\
\hline Coarse Mesh (CM) & 763 & 1407 & $1.9-2.5$ & $2.6-3.5$ & $4.3-7.0$ \\
Median Mesh (MM) & 1513 & 2852 & $0.7-1.5$ & $1.5-2.7$ & $3.2-4.3$ \\
Fine Mesh (FM) & 2979 & 5727 & $0.6-1.2$ & $0.9-1.9$ & $1.9-2.7$ \\
\hline
\end{tabular}


(a)

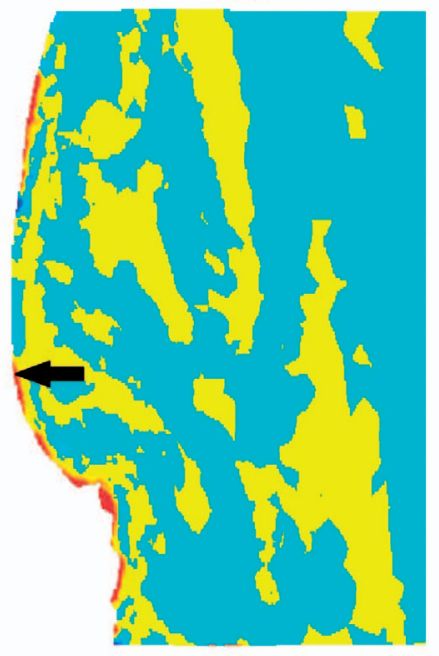

(b)

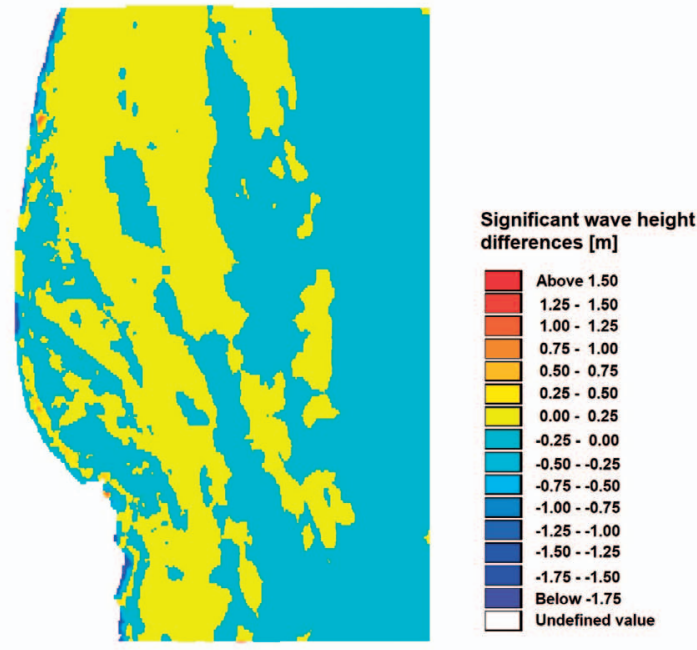

(c)

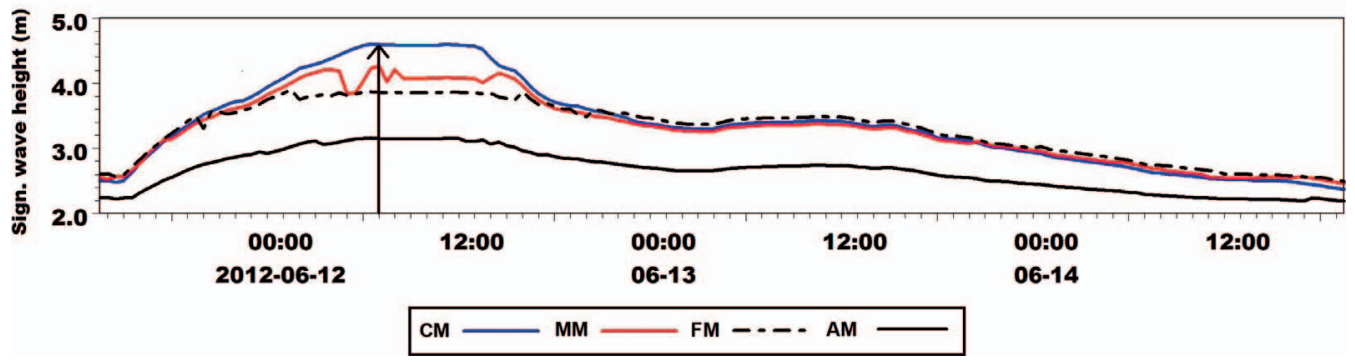

Figure 7. $H_{s}$ difference between simulations with (a) CM and MM and (b) FM and MM, during the peak of the storm on 12 June 2012 , marked with an arrow in part (c); (c) is the time series of $H_{s}$ at a nearshore site $\left(153.44^{\circ},-28.00^{\circ}\right)$, marked with an arrowhead in part (a).

only some small variation in $H_{\mathrm{s}}$ for the entire domain, except at nearshore locations where bottom affect dominated, the baseline mesh was adopted and another mesh zone (i.e. total of four mesh zones) was generated (detailed in the "Bathymetry and Model Mesh" section) along the nearshore, where significant variation of $H_{\mathrm{s}}$ was observed during sensitivity analysis of mesh.

\section{Wave Breaking Index}

Within an intermediate or a shallow-water region, the depthinduced wave breaking parameter (gamma: $\gamma$ ) dominates the energy dissipation of waves due to gradual increases in bottom effects. The relationship between $\gamma$ and deep-water steepness $\left(s_{o}\right)$ calculated in MIKE is shown in Equation (8) (DHI, 2017). The MIKE default $\gamma$ value is 0.8 (DHI, 2017). This value was initially tested during calibration, and it was found that the model underestimated the wave height as shown in Figure 8. In Figure 8, the baseline model was compared against respective measured and default $\gamma$ values provided by MIKE. Although both sides underestimated the wave height relative to the measured data, it was observed that TH stood out more (refer to Figure 8b):

$$
\gamma=0.5+0.4 \tanh \left(33 s_{o}\right)
$$

where, $s_{o}=H_{o} / L_{o}$ is deep-water steepness, $H_{o}$ is wave height, and $L_{o}$ is the wavelength in deep water.

Similar circumstances where wave height was underestimated by the default $\gamma$ value were also encountered by Sedigh $e t$ al. (2016) and Manson (2012). Latter studies suggested applying a $\gamma$ value of 2 and the DHI (2017) manual also recommended applying a value of between 2 and 5 for large waves. Therefore, $\gamma$ values up to 2 were tested during the sensitivity study. However, the $\gamma$ value of 1.5 provided the best result during calibration, based on buoy measurements, for both GC and $\mathrm{TH}$ and this value was adopted.

\section{Wind Conditions}

In previous studies on the Gold Coast region, the sensitivity of wind forcing has not been thoroughly studied. Numerical studies done in other regions, such as Hadadpour et al. (2013), Lavidas and Venugopal (2018), Moeini, Etemad-Shahidi, and Chegini (2010), Rusu, Pilar, and Guedes Soares (2008), and Stopa and Cheung (2014) emphasized the importance of wind forcing. Therefore, by using calibrated energy dissipation coefficients (simulated by measured winds, refer to Table 2), ERA5, and BARRA atmospheric models were analysed in this study. The ERA5 model ( $\sim 30 \mathrm{~km}$, one hourly) had finer temporal resolution, whereas BARRA (12 km, six hourly) had 


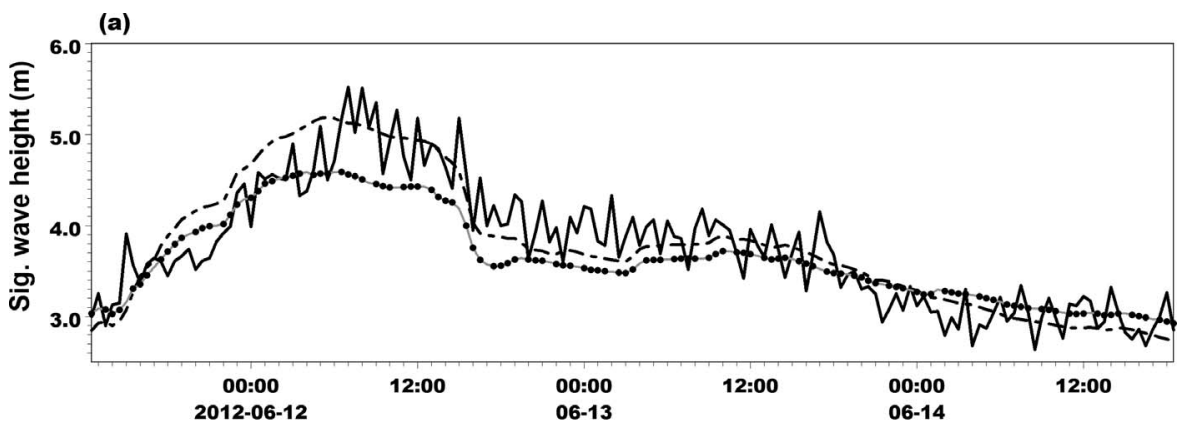

(b)

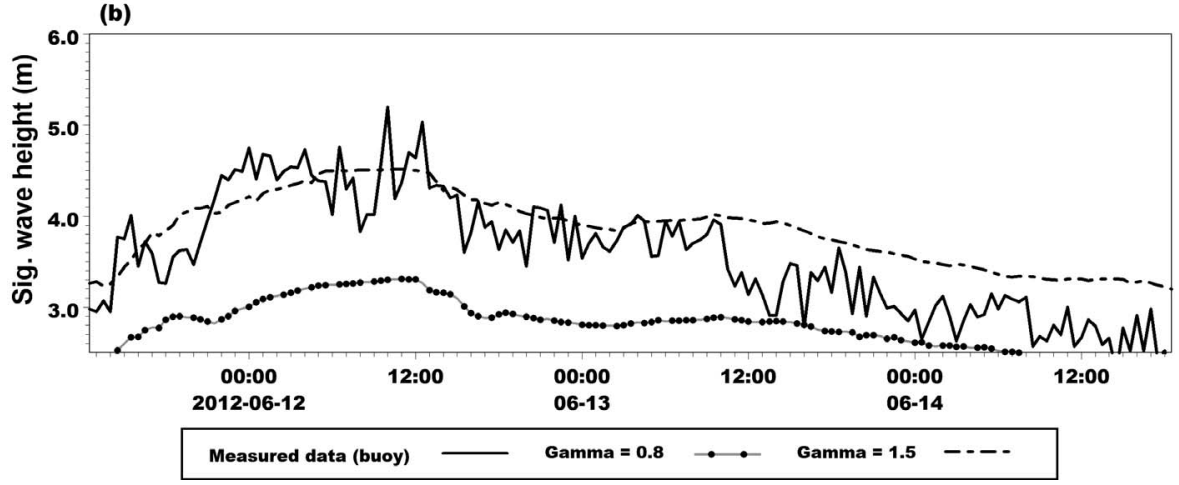

Figure 8. Sensitivity analysis of wave breaking coefficient (gamma) (a) for GC and (b) for TH.

finer spatial resolution. For the sensitivity analysis of wind forcing, the baseline model was replaced with atmospheric models in turn. All three simulated winds results are plotted in Figure $9 \mathrm{a}$ and their respective applied wind speeds at nearshore are plotted in Figure 9b. Since similar outcomes were obtained for both GC and TH results, as an example, only the GC's $H_{s}$ point output results are presented.

From a visual inspection of Figure 9a, it can be concluded that the baseline model underestimated the wave height by approximately up to $0.2 \mathrm{~m}$ (largest discrepancy). The RMSEs for ERA5 and BARRA against the baseline model were computed to be $0.13 \mathrm{~m}$ and $0.24 \mathrm{~m}$ (not tabulated). In Figure $9 \mathrm{~b}$, it can also be observed that the speed of both wind models' predictions was higher than the measured wind speeds. The RMSE and BI of wind speeds with respect to the baseline were also assessed. The RMSE wind speeds of ERA5 and BARRA were $2.84 \mathrm{~m} / \mathrm{s}$ and $3.61 \mathrm{~m} / \mathrm{s}$, respectively, and the BI showed negative ( -2.07 for ERA5 and -2.94 for BARRA) (not tabulated). This indicates that both modelled wind speeds were consistently higher, and this increased the wave height.

The performance of both modelled wind results (i.e. $H_{s}, T_{p}$, and $\theta$ ) was also assessed with respect to measured waves using Equations (4-7), and the results are shown in Table 5. Each modelled wind result from Table 5 was compared with baseline results in Table 3 (calibration period from 11-14 June 2012), and the difference for each respective parameter was negligible. The causes for the discrepancies against measured buoy data, particularly $H_{\mathrm{s}}$, may be owing to wind speed input, as indicated by the DHI (2017) manual, which states that a $10 \%$ error in wind speed can result in a $20 \%$ error for corresponding wave height. Another factor for discrepancies between measured and simulated results could be due to stochastic localized generated wind waves (noises). However, based on the sensitivity of wind assessments, it could be concluded that for nearshore processes where the bottom effect dominates, any type of wind can potentially be used for extreme wave analysis.

Although all wind types (measured, ERA5, and BARRA) were potentially acceptable for nearshore processes in regards to the point output time series, as shown in Figure 9a, b, it would also be interesting to observe variation at offshore. This is because wind speed at open sea could be higher than wind speed nearshore due to fewer obstacles or longer fetch length. To verify this, a point offshore (within the study domain) was extracted from both wind models at the same latitude as the nearshore extraction point and plotted against the measured wind in Figure 9c. This could be done because the baseline model assumed constant wind speed for the entire domain for each time step. From visual observation of Figure 9c, the modelled wind speeds significantly increased at offshore, and this could also reflect wave height generation. This clearly indicates that during simulation of offshore wave height (such as to harvest wave power), wind measured at nearshore could potentially underestimate the wave height offshore (although this needs further analysis due to lack of measure data to verify the results).

To further demonstrate variation in wave height offshore and nearshore due to different wind types, the $H_{s}$ RMSE at each mesh node was compared for both ERA5 and BARRA against the baseline model for the calibration period. The computed results at the nodes are then linearly interpolated 


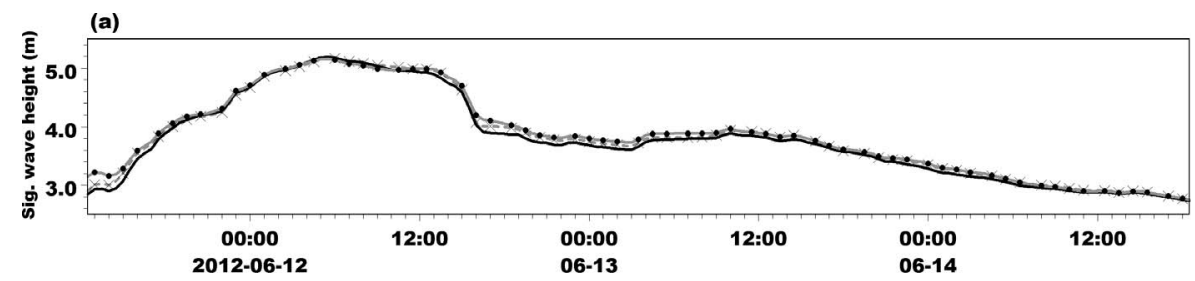

(b)

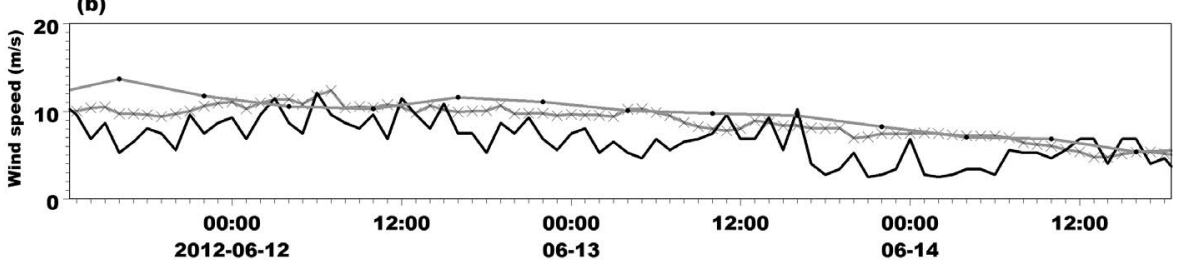

(c)

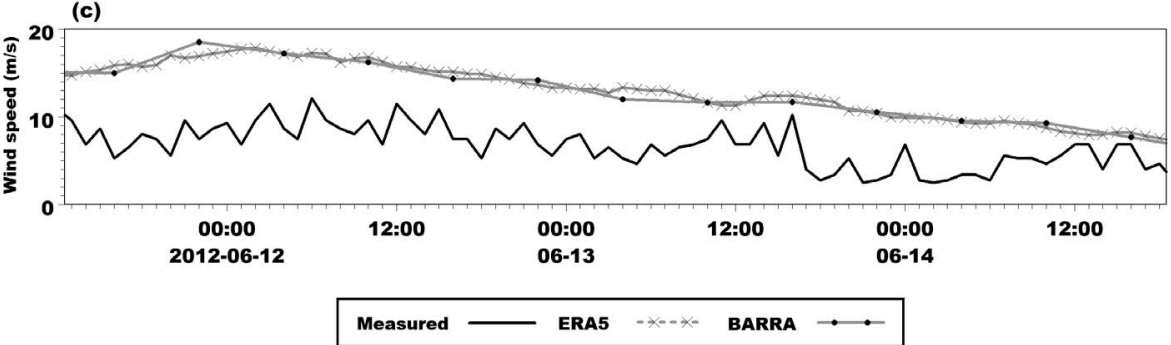

Figure 9. (a) Simulated significant wave height results based on each lateral wind; (b) wind speed nearshore; and (c) wind speed offshore.

spatially by MIKE and are presented in Figure 10, where Figure 10a, b represent the RMSEs of ERA5 and BARRA (against the baseline model), respectively. Both RMSEs (see Figure 10) provided two important pieces of information for the current study region: (1) any type of wind can be applied at a shallow-water location since bottom-induced effects such as refraction and bottom friction are starting to dominate the wave's physical processes; (2) variable wind from an atmospheric model is recommended in deep water as the wind parameter nearshore will not be the same offshore. The aforementioned points demonstrate that, depending on the intended study region (such as nearshore or offshore), the wind forcing must be chosen accordingly. This is also pointed out by previous researchers such as Akpinar and Ponce de León (2016), Lavidas, Venugopal, and Friedrich (2017), Van Vledder and Akpinar (2015), and Wang, Duan, and Dong (2018).

\section{Extreme Weather Analysis}

The developed model (using measured wind) was used to simulate the June 2016 ECL that caused the worst damage in 40 years to some beaches in eastern Australia. The reliability of the simulated model is compared with both measured buoys using Equations (4-7) and they are presented in Table 3 and Figure 11 for both GC and TH. The June 2016 ECL results in Table 3 indicate that model predictions had low errors due to a strong $\mathrm{R}$ and with low RMSE, SI, and BI against their respective measured data. Visual examination of Figure 11 also showed that each respective parameter consisted of reasonable discrepancies due to, for example, offshore wave forcing errors or constant model energy dissipation parameters applied. The wave direction for the $\mathrm{TH}$ showed largest disagreement between simulated and measured data. The RMSE shows over $25^{\circ}$, while BI shows a high positive value, which indicates that the model under-predicted the wave direction (also refer to Figure 11). Modal disagreement with the measured data was also reported in other studies where complex bathymetry was applied (e.g., Guimarães, Farina, and Toldo, 2014). The main contribution to the discrepancy could be constant energy dissipation coefficients (refer to Table 2) applied to the complex bathymetry, where refraction could be significant, and also the assumptions made during calibration (refer to the "Method" section).

\section{Wave Analysis}

To study wave transformation from offshore to nearshore is quite a challenging process without the aid of field measurements. In order to better understand wave transformation during the extreme periods, Hovmöller diagrams (Guimarães, Farina, and Toldo, 2014) were developed for the duration of June 2016 ECL (4 June 2016 to 6 June 2016) storm, which was a northerly storm. However, the predominant wave direction for the current study region is southerly (Splinter et al., 2014). To compare wave transformation due to a southerly storm against a northerly storm, storm wave parameters between 27 June 2012 and 29 June 2012 (i.e. verification period) was applied, which had measured maximum $H \mathrm{~s}$ of $4.57 \mathrm{~m}$ at GC and offshore wave propagation direction on average was $133^{\circ}$. The results for $H_{s}$ (contour) and $\theta$ (indicated by vectors) are displayed in Figure 12. This figure is plotted in a colour scale (from blue: low to red: high). The $\mathrm{x}$-axis and $\mathrm{y}$-axis represent 
Table 5. Qualitative assessment of ERA5 and BARRA against the measured wave data based on half hourly time series.

\begin{tabular}{llllllll}
\hline \hline & \multicolumn{3}{c}{ GC } & & \multicolumn{3}{c}{ TH } \\
\cline { 2 - 3 } \cline { 6 - 7 } & $H_{s}$ & \multicolumn{1}{c}{$T_{p}$} & $\theta$ & & $H_{s}$ & $T_{p}$ & $\theta$ \\
\hline ERA5 & & & & & & \\
R & 0.91 & 0.74 & 0.59 & & 0.88 & 0.73 & 0.65 \\
RMSE & $0.30 \mathrm{~m}$ & $1.21 \mathrm{~s}$ & $14.34^{\circ}$ & & $0.48 \mathrm{~m}$ & $1.06 \mathrm{~s}$ & $6.51^{\circ}$ \\
SI & 0.08 & 0.10 & 0.15 & & 0.13 & 0.09 & 0.08 \\
BI & $-0.05 \mathrm{~m}$ & $1.09 \mathrm{~s}$ & $-11.17^{\circ}$ & $-0.32 \mathrm{~m}$ & $0.91 \mathrm{~s}$ & $2.58^{\circ}$ \\
BARRA & & & & & & \\
R & 0.91 & 0.74 & 0.58 & & 0.89 & 0.73 & 0.64 \\
RMSE & $0.31 \mathrm{~m}$ & $1.21 \mathrm{~s}$ & $14.42^{\circ}$ & & $0.49 \mathrm{~m}$ & $1.06 \mathrm{~s}$ & $6.51^{\circ}$ \\
SI & 0.08 & 0.10 & 0.15 & & 0.14 & 0.09 & 0.08 \\
BI & $-0.08 \mathrm{~m}$ & $1.09 \mathrm{~s}$ & $-11.35^{\circ}$ & $-0.35 \mathrm{~m}$ & $0.91 \mathrm{~s}$ & $2.34^{\circ}$ \\
\hline
\end{tabular}

time and latitude (coastline), respectively. For each type of Hovmöller diagram, wave propagation from intermediate (50 $\mathrm{m})$ to shallow $(10 \mathrm{~m})$ and finally near-wave-breaking $(5 \mathrm{~m})$ depths were assessed.

The results from the Hovmöller diagrams for $H_{s}$ and $\theta$ illustrate that at $50 \mathrm{~m}$ (Figure $12 \mathrm{a}$, b, column 3 ), both $H_{s}$ and $\theta$ remained constant throughout the coastline. As waves approach shallow waters (i.e. $-10 \mathrm{~m}$ and $-5 \mathrm{~m}$ ), wave direction began to vary. Furthermore, depending on the offshore $\theta$, wave attenuation also varied. Northerly storms such as the June 2016 ECL storm had less attenuation in wave height than the southerly storm. As presented in Figure 12a, b, regardless of wave direction, the open-coast environment had the least wave attenuation (i.e. between GC and Palm Beach and around TH), During the northerly swell, the entire coast was exposed to the waves.

\section{Wave Energy Density Spectrum Analysis}

Furthermore, to better understand the wave pattern for the study domain, wave energy density spectra were analysed at the depth of $50 \mathrm{~m}$ for both analysed storms mentioned above, and the results are displayed in Figure 13. This depth was chosen to avoid any significant refraction (Rusu, Bernardino, and Soares, 2014). The minimum refraction effect at $50 \mathrm{~m}$ depth can also be observed in the Hovmöller diagram (see Figure 12a, b, column 3). Due to minimum refraction, the wave energy density spectrum characteristics along the coastline at this depth were also relatively similar (figures not shown). Three spectra were analysed: at the beginning of the storm, at the storm peak, and at the end of the storm (i.e. $H_{s}$ of at least 3 $\mathrm{m})$. The analysed results are displayed in Figure 13. Prior to analysis, the wave energy density spectra were normalized between 0 and 1 . The result showed that regardless of offshore storm conditions, a wide range of wave periods as well as directional spreading were observed. The similarities and differences between the analysed storms are discussed in the next section.

\section{DISCUSSION}

To study wave transformation from offshore to nearshore, Hovmöller diagrams were developed, and to understand the wave pattern, wave energy density spectra were analysed. The Hovmöller diagrams were developed for the June 2016 ECL and the verification period (see Figure 12) to compare the wave transformation due to different offshore wave propagation directions. The wave energy density spectra (see Figure13) were compared at the water depth of $50 \mathrm{~m}$ as recommended by Rusu, Bernardino, and Soares (2014) to understand the wave pattern during the beginning, peak, and end of each storm (i.e. $H_{s}>3 \mathrm{~m}$ ). Both analyses are further discussed in the following subsections.

\section{Wave Analysis}

Hovmöller diagrams were generated as shown in Figure 12 to study wave transformation at the depths of $50 \mathrm{~m}, 10 \mathrm{~m}$, and 5 $\mathrm{m}$, along the latitude (coastline) for the duration (x-axis) of the two storms. Figure 12 represents $H_{\mathrm{s}}$ and its $\theta$, where Figure $12 \mathrm{a}$ is the southerly storm and Figure $12 \mathrm{~b}$ is the northerly (a)

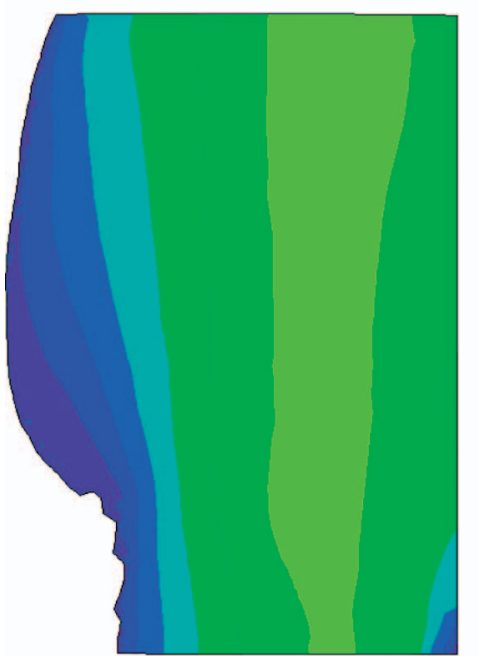

(b)

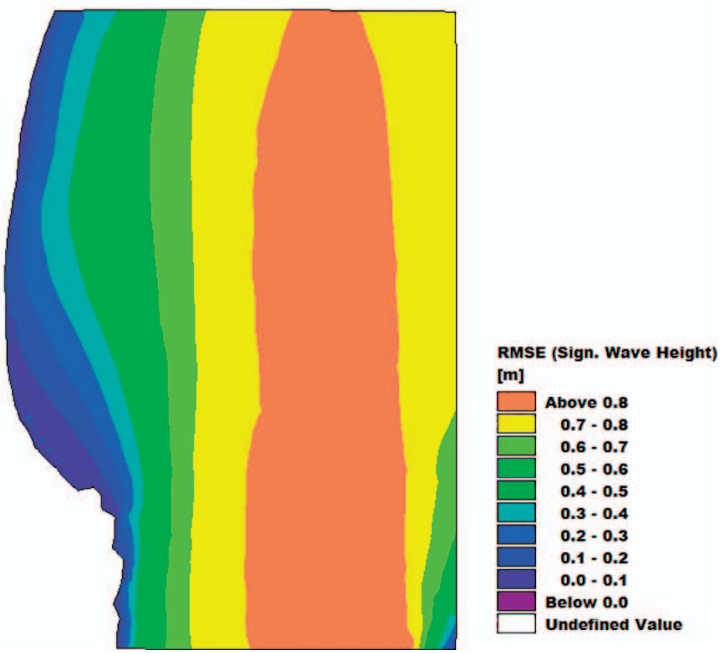

Figure 10. (a) Spatial distribution of RMSE for ERA5 and (b) BARRA against baseline mode for the calibration period (11-14 June 2012). 


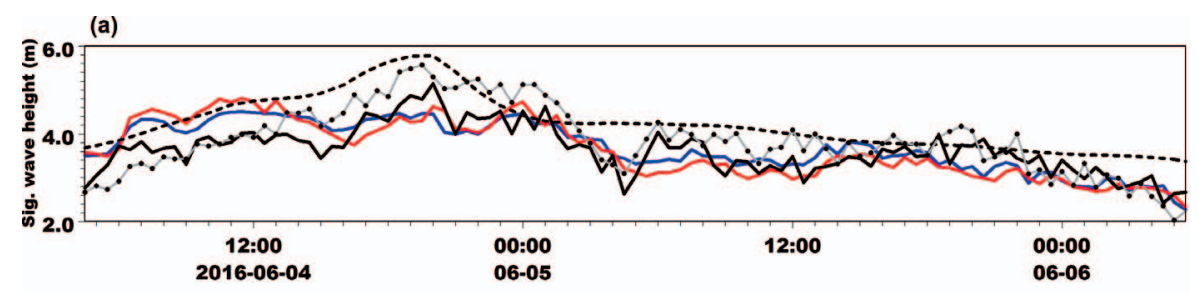

(b)

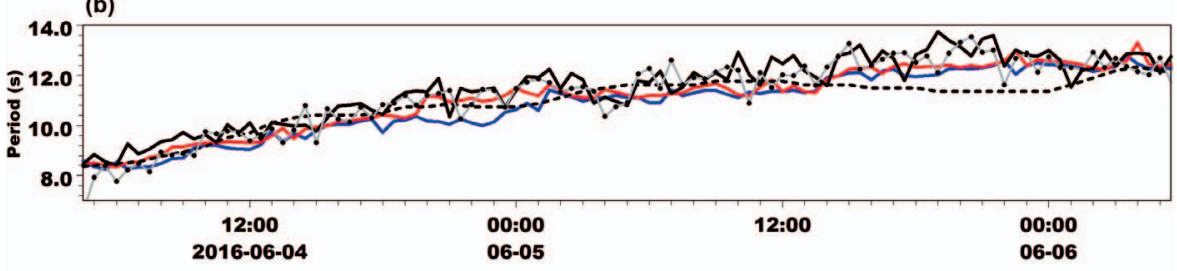

(c)

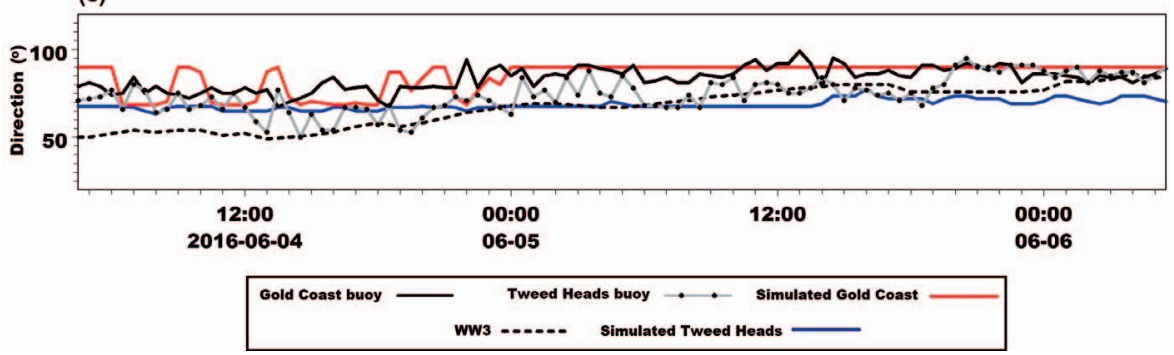

Figure 11. June 2016 ECL simulated results for both GC and TH plotted against their respective measured data and WW3 (offshore) wave conditions.

storm. Based on the wave refraction pattern (i.e. vector heads in Figure 12) at the depth of $10 \mathrm{~m}$ (Figure 12a, b, column 2) and $5 \mathrm{~m}$ (Figure 12a, b, column 1), the coastline can be divided into three zones: (1) Zone 1 (from GC to Surfers Paradise); (2) Zone 2 (between Surfers Paradise and Palm); and (3) Zone 3 ( $-28.14^{\circ}$ to $\mathrm{TH}$ ). Within each zone, it was observed that depending on the offshore storm wave direction ( $-50 \mathrm{~m}$, Figure $12 \mathrm{a}$, b, column 3 , nearshore wave attenuation can also vary significantly due to wave refraction caused by the orientation of coastline.

From Figure 12, it is observed that longshore wave refraction (vector) existed despite offshore wave propagation direction. For the southerly offshore storm, waves experienced the least refraction at Zone 1 nearshore (see Figure 12a, columns 1 and 2); that is, waves refracted to the east. However, within Zone 3 nearshore (for the same offshore storm), waves experienced the greatest refraction (i.e. offshore southerly waves became northerly at nearshore). Such a significant refraction was mainly caused by the headland (Vieira Da Silva, Murray, and Strauss, 2018). However, during the northerly offshore storm, waves at nearshore (see Figure 12b, columns 1 and 2) experienced the least refraction along Zone 1 and 2 (i.e. -10 $\mathrm{m}$ as well as $-5 \mathrm{~m}$ ). Within Zone 3 , offshore northerly storm waves further refracted to northerly ones in shallow water depths $(-10 \mathrm{~m}$ and -5$)$. This demonstrated that within the vicinity of the headland, despite offshore propagation direction, waves are being refracted to leeward of headlands at nearshore. Based on the analysis of both offshore wave directions, within Zone 3, it is apparent that wave refraction is independent of offshore wave direction. This could explain why within the vicinity of Palm Beach, more erosion is observed due to the disturbance of longshore wave propagation pattern.

From Figure 12, it can also be observed that longshore wave attenuation (colour contour) existed. From the southerly storm (Figure 12a), comparing the wave height at the depth of $50 \mathrm{~m}$ (Figure 12a, column 3) and $5 \mathrm{~m}$ (Figure 12a, column 1), the longshore wave attenuation was relatively even in Zones 1 and 2 . However, in Zone 3, wave attenuation varied. From latitude $-28.14^{\circ}$ to Bilinga (i.e. leeward of headland, see Figure 1 ), wave attenuation was the highest within the study domain. In contrast, from Bilinga to TH (i.e. vicinity of the headland, see Figure 1), wave attenuation was minimal throughout the storm duration. On the contrary, during the northerly offshore storm (Figure 12b), wave attenuation was minimal along the coastline. This implies that the wave would dissipate close to the shore. Similar to the southerly storm direction, the wave attenuation in Zone 3 would likely not occur throughout the duration of the storm. This analysis shows that offshore wave direction plays an important role in wave refraction and attenuation, which is in line with the findings of de Winter and Ruessink (2017), Harley et al. (2017), Mortlock et al. (2017), and Sanuy and Jiménez (2019), and also with the findings of Vieira Da Silva, Murray, and Strauss (2018), who studied longshore wave refraction and attenuation using approximately 20 years of wave data from the same region.

The wave refraction and attenuation mentioned above is caused by the nature of the continental shelf and the orientation of the isobaths as pointed out by Guimarães, 

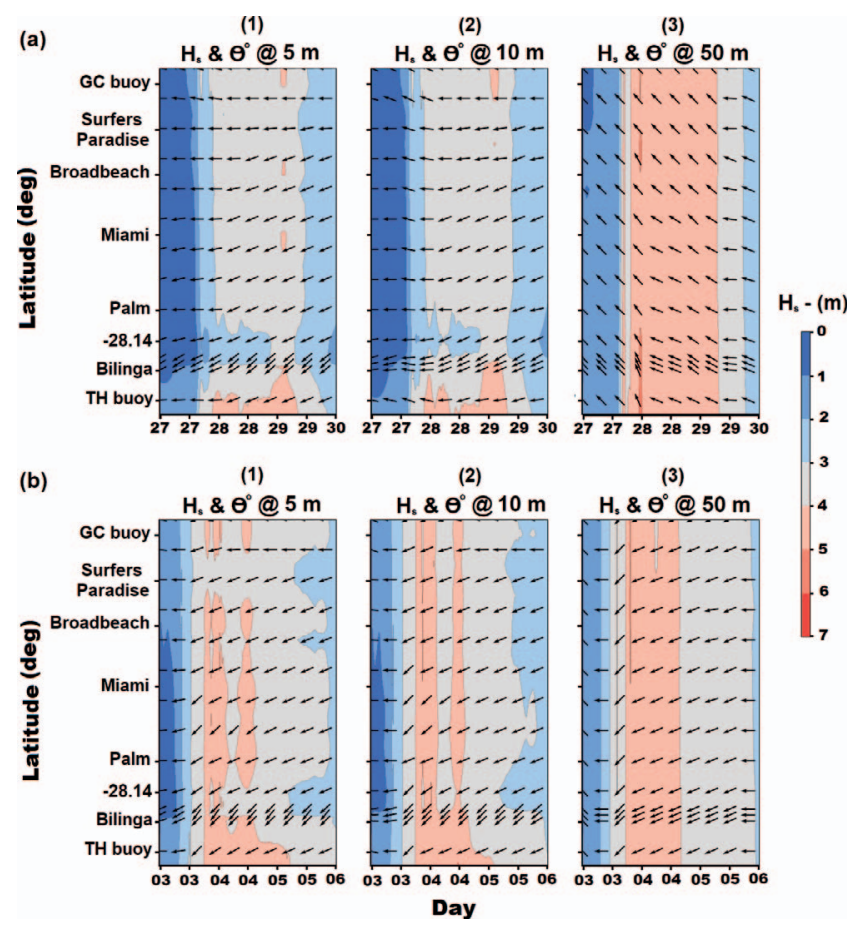

Figure 12. Hovmöller diagrams, where the $\mathrm{x}$-axis and $\mathrm{y}$-axis are time and latitude (coastline), respectively; (a) is southerly and (b) is northerly offshore wave direction. The contour and vectors represent $H_{s}$ and $\theta$, respectively.

Farina, and Toldo (2014). The Gold Coast continental shelf is narrow and steep (see Figure 1) and hence, wave interactions with bathymetry would be at a minimum, resulting in low wave attenuation (Chapman, 1980). In addition, the orientation of the isobaths at the Gold Coast is parallel to the east at the north and to northeast at the south (Strauss et al., 2007), and therefore waves tend to refract east at the north and northeast at the south. However, between Palm Beach and Bilinga (from
$30 \mathrm{~m}$ depth to the shore), two bathymetry features were observed (see Figure 1): (1) a wider continental shelf (see Figure $1 \mathrm{~b}$ of isobath) than other nearshore locations (i.e. bathymetry slope steepness decreases); and (2) the orientation of isobaths is northeast. Due to these two unique features, as well as the presence of the nearby headland, more waves from the southerly swells are refracted and significant wave attenuations were observed in Figure 12. However, due to abnormal northerly swells (such as the June 2016 ECL), the coast essentially became an open coast and the refraction and wave attenuation became minimal. Therefore, this analysis indicates the model agrees with bathymetric features of this study location (see Figure 1) as well as with other studies (Guimarães, Farina, and Toldo, 2014; Strauss et al., 2007; Vieira Da Silva, Murray, and Strauss, 2018).

Despite the model showing highest wave attenuation between latitude $-28.14^{\circ}$ and Bilinga beach nearshore (see Figure 12a), numerous engineering works have been performed at Palm Beach (Splinter et al., 2014). This could be due to strong wave refraction in Zone 3, regardless of offshore wave direction. The nearshore waves in Zone 3 are being refracted to the northeast, and such a strong refraction might disturb the longshore sediment pattern.

\section{Wave Energy Density Spectrum Analysis}

To better understand the wave pattern induced by both storms for the study domain, normalized (between 0 and 1) wave energy density spectra were analysed (refer to Figure 13) at the depth of $50 \mathrm{~m}$ to avoid any significant refraction (Rusu, Bernardino, and Soares, 2014). Due to the lack of longshore variation in refraction, the results in Figure 13 were similar along the coastline. Three storm wave energy density spectra were analysed during the beginning, peak, and end of both storms. Regardless of the storm direction, the model detected wide variation of $T_{\mathrm{p}}$ and $\theta$ of simulated waves.

During the beginning of the southerly storm, the peak energy was from south-southeast (Figure 13a) and as the storm peaked, the direction of peak energy shifted to the east (Figure 13b). When the storm ended (Figure 13c), the peak energy (a)

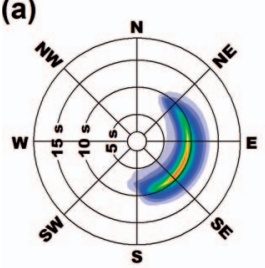

(d)

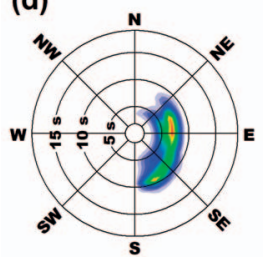

(b)

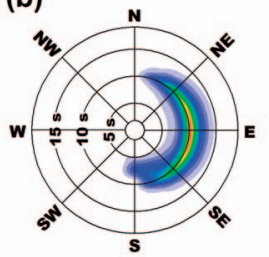

(e)

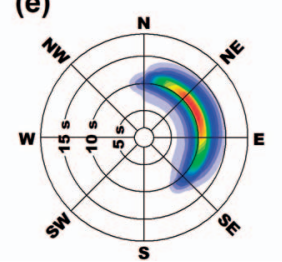

(c)

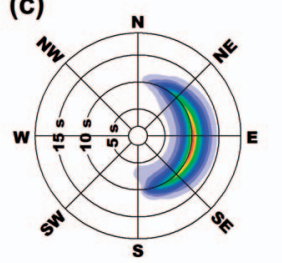

(f)

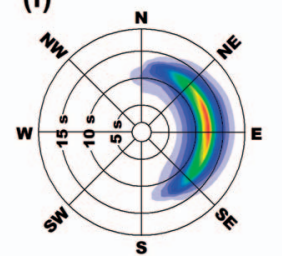

Normalized Energy

Density

Above 0.95 $0.90 \cdot 0.95$ $0.85-0.90$ $0.80 \cdot 0.85$ $0.75 \cdot 0.80$ $0.70-0.75$ $0.65 \cdot 0.70$ $0.60-0.65$ $0.55 \cdot 0.60$ $0.50-0.55$ $0.45-0.50$ $0.40 \cdot 0.45$ $0.35-0.40$ $0.30-0.35$ $0.25-0.30$ $0.20 \cdot 0.25$ $0.15 \cdot 0.20$ $0.15 \cdot 0.20$
$0.10 \cdot 0.15$ $0.05 \cdot 0.10$ Below 0.05

Figure 13. Energy spectrums for the southerly storm (a), (b), and (c) and northerly storm (d), (e), and (f). The beginning of the storm is represented by (a) and (d), the peak of the storm by (b) and (e), and the end of the storm by (c) and (f). 
remained steady at the east. Throughout the southerly storm, the $T_{\mathrm{p}}$ ranged from $5 \mathrm{~s}$ to $15 \mathrm{~s}$ and $\theta$ was from north to south. In contrast, during the beginning of the northerly storm (Figure 13d), the model detected two energy peaks with different intensities; however, the easterly peak had wider range than the south-easterly peak that are approximately $90^{\circ}$ apart. This indicated bidirectional waves were detected by the model, which were composed of storm-induced waves (i.e. easterly direction) and frequently occurring waves from the predominant direction (i.e. south-easterly direction). During the peak of the storm, the peak energy shifted to the east-northeast (Figure 13e) and at the end of the northerly storm the peak energy shifted to an easterly direction (Figure 13f).

When the energy densities of the two storms were compared, both similarities and differences were detected. During the beginnings of the storms (Figure 13a, d), the range of directional spreading was similar; however, the range of periods showed some dissimilarities. During the northerly storm (Figure 13d), the $T_{\mathrm{p}}$ ranged between $5 \mathrm{~s}$ to $10 \mathrm{~s}$. This indicated that the model detected more local wave characteristics (i.e. sea-waves) than storm wave characteristics (i.e. swell-waves). In addition, bidirectional peak energies were detected which were, as mentioned above, $90^{\circ}$ apart and the directional spreading of peak energy coverage was in narrow range. In the southerly storm, a swell-wave with unidirectional peak energy was detected and the directional spreading of the peak energy covered a wider range. This demonstrated that during the beginning of the southerly storm wave, the wave energy was more widely spread than the northerly storm wave.

During the peaks of the storms (Figure 13b, e), the range of period was similar for both storm wave directions. During both directions, the model detected more swell wave characteristics and the period ranged from approximately $6 \mathrm{~s}$ to $15 \mathrm{~s}$. However, the direction of the energy and period coverage was not the same. The northerly storm produced a wide range of energy from the north to southeast. The peak energy, with a wider period range (between $10 \mathrm{~s}$ and $\sim 12 \mathrm{~s}$ ), was detected between the northeast and east. However, in the south to southeast quadrant, the model did not detect any activity for the northerly storm. This also implies that during the northerly storm, regular patterns, such as the longshore sediment transport pattern, would be forcefully reversed. In contrast, during the peak of the southerly storm, it produced a broader range of energy from the north to south direction. Also, the peak energy covered the northeast to southeast with a narrow period range, approximately $10 \mathrm{~s}$.

At the end of the storms (Figure 13c, f), both storms covered energies from north to south with a similar period range between $5 \mathrm{~s}$ and $\sim 15 \mathrm{~s}$. The peak periods, however, were different. The peak period of the southerly storm was approximately $11 \mathrm{~s}$ with wider coverage (from northeast to southeast). However, for the northerly storm, the peak period was approximately $13 \mathrm{~s}$, covering a smaller range between eastnortheast and east-southeast. For the southerly storm, the direction of the peak energy at the end of the storm remained consistent with the storm peak spectrum. On the other hand, for the northerly storm, the peak energy shifted to an easterly direction.
Studying wave transformation from offshore to nearshore at a nonlinear open coast with micro tidal environment, it has been demonstrated in this study that depending on offshore storm wave direction, wave refraction and attenuation along nearshore can vary considerably. The study of wave transformation also demonstrated that at the leeward of headland, wave refraction is independent of offshore wave propagation direction, where unusual erosion is observed due to disturbance of longshore wave pattern. In addition, analysing the wave energy density spectrum indicated that both period and directional spreading can vary, and multidirectional waves may also be observed.

\section{CONCLUSIONS}

In this paper, a high-resolution wind-wave model was configured to study the storm wave using MIKE. The lack of sensitivity studying wind and mesh resolution within the study domain prompted the feasibility study of various types of winds (ERA5, BARRA, and measured wind) and different mesh resolutions. It was found that at nearshore, where the bottom effect dominates the wave's physical processes, using the modelled wind field would not be necessary and the mesh resolution plays an important role in wave height. However, the opposite trend was observed for offshore. This study focused on nearshore processes and, thus, measured wind with four zones with varying mesh resolutions was applied for further analysis. The developed model was then verified and two storms with different offshore wave propagation directions (southerly and northerly) were analysed.

To assess the storm wave transformation, Hovmöller diagrams provide better understanding for the entire coastline. Hovmöller diagrams show that regardless of offshore wave direction, beaches between latitude -28.14 and Bilinga had the greatest wave refraction (due to a nearby headland and the orientation of the coastline) leading to significant wave attenuation. In contrast, at beaches within the vicinity of $\mathrm{TH}$, attenuation is at a minimum throughout the duration of storm (due to the open-coast environment). When the storms were analysed based on direction, the southerly storm showed prominent wave refraction and attenuation for the entire coastline compared to the northerly storm. For the northerly storm, the model implies that beaches will essentially become an open-coast environment with minimum wave refraction and attenuation. Thus, Gold Coast beaches are more exposed to northerly storms.

The analysis of wave energy density spectra (at $-50 \mathrm{~m}$ ) provides further understanding of the wave pattern developed by both storms. During the beginning of the storm, the southerly storm produced a unidirectional peaked wave energy density spectrum, whereas the northerly storm produced bidirectional peaked wave energy density spectra from the opposite direction. At its peak, the southerly storm shifted predominantly to the eastern direction. In terms of the northerly storm, the predominant direction was between $\mathrm{NE}$ and $\mathrm{E}$ with unidirectional wave energy density spectrum. By the end of the storms, both storms' wave energy density spectra remained steadily at the east. Thus, wave patterns vary based on offshore storm wave direction. 
In summary, this assessment demonstrated that at nearshore, where the bottom effect is dominant, any type of wind (measured or reanalysed) can be used. However, as the bottom effect reduces, reanalysed wind is potentially more suitable, although this needs further investigation. This study also demonstrates that depending on offshore storm wave propagation direction, wave refraction and attenuation can vary significantly along the coast. This variation is mainly due to waves experiencing different bathymetric features (i.e. orientation of isobaths) and degree of sheltering provided by the headland. As such, beaches will also experience different levels of storm-induced coastal damage. Thus, due to climate change (both short- and long-term), a shift in wave direction can disrupt longshore wave pattern, as demonstrated in this study, that may cause further complications (such as beach erosion) nearshore. Therefore, more directional-based coastal research is required to protect beaches due to climate change.

\section{ACKNOWLEDGMENTS}

The authors thank DHI for the MIKE product. Measured waves were obtained from the Queensland Government. WW3 Global Wave Model data was provided by PacIOOS (www.pacioos.org), which is a part of the U.S. Integrated Ocean Observing System $\left(\operatorname{IOOS}^{\circledR}\right)$, funded in part by National Oceanic and Atmospheric Administration (NOAA) Award \#NA16NOS0120024. The bathymetry dataset was from the CIAT-CSI SRTM website (http://srtm.csi.cgiar.org). The measured wind dataset was obtained from the Australian Government Bureau of Meteorology and modelled wind (BARRA) was from the Bureau of Meteorology high-resolution atmospheric reanalysis for Australia (BARRA) (http://www.bom.gov.au/metadata/ catalogue/view/ANZCW0503900566.shtml?template=full). ERA5 modelled wind "contains modified Copernicus Climate Change Service Information 2019" and neither the European Commission nor ECMWF is responsible for any use that may be made of the Copernicus information or data it contains. The authors would also like to thank two anonymous reviewers for their constructive comments. This research did not receive any specific grant from funding agencies in the public, commercial, or not-forprofit sectors.

\section{LITERATURE CITED}

Aboobacker, V.M.; Vethamony, P.; Sudheesh, K., and Rupali, S.P., 2009. Spectral characteristics of the nearshore waves off Paradip, India during monsoon and extreme events. Natural Hazards, 49(2), 311-323.

Akpinar, A. and Ponce de León, S., 2016. An assessment of the wind re-analyses in the modelling of an extreme sea state in the Black Sea. Dynamics of Atmospheres and Oceans, 73, 61-75.

Allard, R.; Rogers, E., and Carroll, N.S., 2002. User's Manual for the Simulating Waves Nearshore Model (SWAN). Delft, The Netherlands: Delft University of Technology.

Allen, M. and Callaghan, J., 1999. Extreme wave conditions for the south Queensland coastal region. Proceedings of the 14th Australasian Coastal and Ocean Engineering Conference and the 7th Australasian Port and Harbour Conference (Barton, Australia Capital Territory), pp. 5-10.

Allen, M.S. and Andrews, M.J., 1997. Assessment of directional wave climate variability for a sand bypassing project. Proceedings of the 13th Australasian Coastal and Ocean Engineering Conference and the 6th Australasian Port and Harbour Conference (Christchurch, New Zealand), pp. 903-908.

Aydoğan, B. and Ayat, B., 2018. Spatial variability of long-term trends of significant wave heights in the Black Sea. Applied Ocean Research, 79, 20-35.

Burston, J.; Taylor, D., and Garber, S., 2016. Contextualizing the return period of the June 2016 East Coast Low: Waves, water levels and erosion. Proceedings of 25th NSW Coastal Conference (Coffs Harbour, New South Wales), pp. 9-11.

Callaghan, D.P.; Nielsen, P.; Short, A., and Ranasinghe, R., 2008 Statistical simulation of wave climate and extreme beach erosion. Coastal Engineering, 55(5), 375-390.

Campos, R.M.; Alves, J.H.G.M.; Soares, C.G.; Guimaraes, L.G., and Parente, C.E., 2018. Extreme wind-wave modeling and analysis in the south Atlantic Ocean. Ocean Modelling, 124, 75-93.

Casas-Prat, M.; Wang, X.L., and Sierra, J.P., 2014. A physical-based statistical method for modeling ocean wave heights. Ocean Modelling, 73, 59-75.

Castelle, B.; Le Corre, Y., and Tomlinson, R., 2008. Can the gold coast beaches withstand extreme events? Geo-Marine Letters, 28(1), 2330 .

Cavaleri, L., 2009. Wave modeling-Missing the peaks. Journal of Physical Oceanography, 39(11), 2757-2778.

Cavaleri, L. and Bertotti, L., 2006. The improvement of modelled wind and wave fields with increasing resolution. Ocean Engineering, 33(5-6), 553-565.

Chapman, D.M., 1980. Coastal erosion and the sediment budget, with special reference to the Gold Coast, Australia. Coastal Engineering, 4, 207-227.

Cheung, K.F., 2010. WaveWatch III (WW3) Global Wave Model, Pacific Islands Ocean Observing System (PacIOOS). https://paepaha.pacioos.hawaii.edu/erddap/griddap/ww3_global.html

Copernicus Climate Change Service (C3S), 2017. ERA5: Fifth generation of ECMWF atmospheric reanalyses of the global climate. Reading, United Kingdom: ECMWF.

de Winter, R.C. and Ruessink, B.G., 2017. Sensitivity analysis of climate change impacts on dune erosion: Case study for the Dutch Holland coast. Climatic Change, 141(4), 685-701.

DHI, 2017. MIKE 21 Spectral Wave FM, Spectral Wave Module, User Guide. https://manuals.mikepoweredbydhi.help/2017/Coast_and Sea/MIKE21SW.pdf

Fonseca, R.B.; Gonçalves, M., and Guedes Soares, C., 2017. Comparing the performance of spectral wave models for coastal areas. Journal of Coastal Research, 33(2), 331-346.

Granger, K. and Hayne, M., 2001. Natural Hazards \& Risks They Pose to South East Queensland. Camberra, Australian Capital Territory: AGSO-Geoscience Australia, 389p.

Guimarães, P.V.; Farina, L., and Toldo, E.E., 2014. Analysis of extreme wave events on the southern coast of Brazil. Natural Hazards and Earth System Sciences, 14(12), 3195-3205.

Hadadpour, S.; Moshfeghi, H.; Jabbari, E., and Kamranzad, B., 2013. Wave hindcasting in Anzali, Caspian Sea: A hybrid approach. Journal of Coastal Research, 65(10065), 237-242.

Harley, M.D.; Turner, I.L.; Kinsela, M.A.; Middleton, J.H.; Mumford, P.J.; Splinter, K.D.; Phillips, M.S.; Simmons, J.A.; Hanslow, D.J., and Short, A.D., 2017. Extreme coastal erosion enhanced by anomalous extratropical storm wave direction. Scientific Reports, $7(1), 1-9$.

Hasselmann, K.; Barnett, T.P.; Bouws, E.; Carlson, H.; Cartwright, D.E.; Eake, K.; Euring, J.A.; Gicnapp, A.; Hasselmann, D.E. Kruseman, P.; Meerburg, A.; Mullen, P.; Olbers, D.J.; Richren, K.; Sell, W., and Walden, H., 1973. Measurements of Wind-Wave Growth and Swell Decay During the Joint North Sea Wave Project (JONSWAP). http://resolver.tudelft.nl/uuid:f204e188-13b9-49d8 a6dc-4fb7c20562fc

Hasselmann, K.; Hasselmann, S.; Bauer, E.; Janssen, P.A.E.M.; Komen, G.J.; Bertotti, L.; Lionello, P.; Guillaume, A.; Cardone, V.C.; Greenwood, J.A.; Reistad, M.; Zambresky, L., and Ewing, J.A., 1988. The WAM model-A third generation ocean wave prediction model. Journal of Physical Oceanography, 18(12), 17751810. 
Jarvis, A.; Reuter, H.I.; Nelson, A., and Guevara, E., 2008. Hole-Filled Seamless SRTM Data V4, International Centre for Tropical Agriculture (CIAT). http://srtm.csi.cgiar.org

Kamranzad, B.; Etemad-Shahidi, A., and Kazeminezhad, M.H., 2011. Wave height forecasting in Dayyer, the Persian Gulf. Ocean Engineering, 38(1), 248-255.

Karunarathna, H.; Pender, D.; Ranasinghe, R.; Short, A.D., and Reeve, D.E., 2014. The effects of storm clustering on beach profile variability. Marine Geology, 348, 103-112.

Kerr, P.C.; Martyr, R.C.; Donahue, A.S.; Hope, M.E.; Westerink, J.J.; Luettich, R.A., Jr.; Kennedy, A.B.; Dietrich, J.C.; Dawson C., and Westerink. H.J., 2013. US IOOS coastal and ocean modeling testbed: Evaluation of tide, wave, and hurricane surge response sensitivities to mesh resolution and friction in the Gulf of Mexico. Journal of Geophysical Research: Oceans, 118(9), 4633-4661.

Lavidas, G. and Venugopal, V., 2018. Application of numerical wave models at European coastlines: A review. Renewable and Sustainable Energy Reviews, 92, 489-500.

Lavidas, G.; Venugopal, V., and Friedrich, D., 2017. Sensitivity of a numerical wave model on wind re-analysis datasets. Dynamics of Atmospheres and Oceans, 77, 1-16.

Lewis, J.; Mortensen, S.; Stuart, G.; Dronen, N.; Tomlinson, R., and Hunt, S., 2010. Detailed Assessment of Extreme Coastal Erosion and Storm Surge Vulnerability of Central Gold Coast Beaches. https://www.coastalconference.com/2010/papers 2010/ James\%20Lewis\%20full\%20paper.pdf

Lisboa, R.C.; Teixeira, P.R., and Fortes, C.J., 2017. Numerical evaluation of wave energy potential in the south of Brazil. Energy, 121, 176-184.

Manson, G.K., 2012. Configuration of Mike21 for the simulation of nearshore storm waves, currents, and sediment transport: Brackley Bight, Prince Edward Island. Geological Survey of Canada, Open File 6736

Moeini, M.H. and Etemad-Shahidi, A., 2007. Application of two numerical models for wave hindcasting in Lake Erie. Applied Ocean Research, 29(3), 137-145.

Moeini, M.H.; Etemad-Shahidi, A., and Chegini, V., 2010. Wave modeling and extreme value analysis off the northern coast of the Persian Gulf. Applied Ocean Research, 32(2), 209-218.

Mortlock, T.R.; Goodwin, I.D.; McAneney, J.K., and Roche, K., 2017. The June 2016 Australian East Coast Low: Importance of wave direction for coastal erosion assessment. Water, 9(2), 121.

Padilla-Hernández, R.; Perrie, W.; Toulany, B., and Smith, P.C., 2007. Modeling of two northwest Atlantic storms with third-generation wave models. Weather and Forecasting, 22(6), 1229-1242.

Ramon, J.; Lledo, L.; Torralba, V.; Soret, A., and Doblas-Reyes, F.J., 2019. What global reanalysis best represents near-surface winds? Quarterly Journal of the Royal Meteorological Society, 145(724), 3236-3251.

Rogers, W.E.; Dykes, J.D.; Wang, D.; Carroll, S.N., and Watson, K., 2012. Validation Test Report for WAVEWATCH III. Washington, D.C.: Naval Research Laboratory, Memorandum Report 7320-12$9425,75 \mathrm{p}$.

Rusu, L.; Bernardino, M., and Soares, C.G., 2014. Wind and wave modelling in the Black Sea. Journal of Operational Oceanography, 7(1), 5-20.

Rusu, L.; Pilar, P., and Guedes Soares, C., 2008. Hindcast of the wave conditions along the west Iberian coast. Coastal Engineering, $55(11), 906-919$.

Sanuy, M. and Jiménez, J.A., 2019. Sensitivity of storm-induced hazards in a highly curvilinear coastline to changing storm directions. The Tordera Delta Case (NW Mediterranean). Water, 11(4), 747.

Sedigh, M.; Tomlinson, R.; Cartwright, N., and Etemad-Shahidi, A., 2015. Numerical simulation of the morphodynamics of the Gold Coast Seaway. Proceedings of the 21st International Congress on Modelling and Simulation (MODSIM2015) (Gold Coast, Queensland, Australia), pp. 1247-1253.
Sedigh, M.; Tomlinson, R.; Cartwright, N., and Etemad-Shahidi, A. 2016. Numerical modelling of the Gold Coast Seaway area hydrodynamics and littoral drift. Ocean Engineering, 121, 47-61.

Splinter, K.D.; Carley, J.T.; Golshani, A., and Tomlinson, R., 2014. A relationship to describe the cumulative impact of storm clusters on beach erosion. Coastal Engineering, 83, 49-55.

Splinter, K.D. and Palmsten, M.L., 2012. Modeling dune response to an East Coast Low. Marine Geology, 329, 46-57.

Stopa, J.E. and Cheung, K.F., 2014. Intercomparison of wind and wave data from the ECMWF Reanalysis Interim and the NCEP Climate Forecast System Reanalysis. Ocean Modelling, 75, 65-83.

Strauss, D.; Deshoulieres, A.; Tomlinson, R., and Lane, C., 2007. Near-shore wave condition forecasts for the Southeast Queensland region. Proceedings Inaugural Queensland Coastal Conference (Queensland, Australia), pp. 17-20.

Strauss, D.; Mirferendesk, H., and Tomlinson, R., 2007. Comparison of two wave models for Gold Coast, Australia. In: Lemckert, C.J. (ed.), Proceedings of the 9th International Coastal Symposium. Journal of Coastal Research, Special Issue No. 50, pp. 312-316.

Strauss, D.; Splinter, K.D., and Tomlinson, R., 2011. Beach nourishment and coastal protection along the Gold Coast, Australia: A case study at Palm Beach. Proceedings of the Coastal Sediments 2011 (Miami, Florida), pp. 71-84.

Strauss, D. and Tomlinson, R., 2009. Modelling transitions between barred beach states on a straight coast. In: Mizuguchi, M. and Sato, S. (eds.), Proceedings of Coastal Dynamics 2009: Impacts of Human Activities on Dynamic Coastal Processes (Tokyo, Japan), pp. 1-11.

Su, C.H.; Eizenberg, N.; Steinle, P.; Jakob, D.; Fox-Hughes, P.; White, C.J.; Rennie, S.; Franklin, C.; Dharssi, I., and Zhu, H., 2019 BARRA v1.0: The Bureau of Meteorology atmospheric highresolution regional reanalysis for Australia. Geoscientific Model Development, 12(5), 2049-2068.

Sverdrup, H.U. and Munk, W.H., 1947. Wind Sea and Swell: Theory of Relations for Forecasting. Washington, D.C.: U.S. Department of the Navy Hydrographic Office, Publication No. 601, 44p.

The WAVEWATCH III Development Group (WW3DG), 2016. User Manual and System Documentation of WAVEWATCH III Version 5.16. Court College Park, Maryland: NOAA/NWS/NCEP/MMAB, Technical Note 329, 326p.

Turner, I.L.; Harley, M.D.; Short, A.D.; Simmons, J.A.; Bracs, M.A.; Phillips, M.S., and Splinter, K.D., 2016. A multi-decade dataset of monthly beach profile surveys and inshore wave forcing at Narrabeen, Australia. Scientific Data, 3(1), 1-13.

Turner, I.L.; Aarninkhof, S.G.J., and Holman, R.A., 2006. Coastal imaging applications and research in Australia. Journal of Coastal Research, 2006(221), 37-48.

U.S. Army, (1984). Shore Protection Manual. Washington, D.C.: U.S. Army Engineer Waterways Experiment Station, U.S. Government Printing Office, $337 \mathrm{p}$.

Van Vledder, G.P. and Akpinar, A., 2015. Wave model predictions in the Black Sea: Sensitivity to wind fields. Applied Ocean Research, 53, 161-178.

Venugopal, V.; Davey, T.; Girard, F.; Smith, H.; Cavaleri, L.; Bertotti, L., and Mauro, S., 2011. Wave Model Intercomparison. Brussels, Belgium: Commission of The European Communities, Deliverable $2.4,47 \mathrm{p}$.

Vieira Da Silva, G.; Murray, T., and Strauss, D., 2018. Longshore wave variability along non-straight coastlines. Estuarine, Coastal and Shelf Science, 212, 318-328.

Wang, T.; Yang, Z.; Wu, W.C., and Grear, M., 2018. A sensitivity analysis of the wind forcing effect on the accuracy of large-wave hindcasting. Journal of Marine Science and Engineering, 6(4), 139

Wang, Z.; Duan, C., and Dong, S., 2018. Long-term wind and wave energy resource assessment in the South China sea based on 30year hindcast data. Ocean Engineering, 163, 58-75.

Wilson, B.W., 1965. Numerical prediction of ocean waves in the North Atlantic for December, 1959. Deutsche Hydrografische Zeitschrift, 18(3), 114-130. 